\title{
Proposed standardized definitions for vertical resolution and uncertainty in the NDACC lidar ozone and temperature algorithms - Part 3: Temperature uncertainty budget
}

\author{
Thierry Leblanc ${ }^{1}$, Robert J. Sica ${ }^{2}$, Joanna A. E. van Gijsel $^{3}$, Alexander Haefele ${ }^{4}$, Guillaume Payen ${ }^{5}$, and \\ Gianluigi Liberti ${ }^{6}$ \\ ${ }^{1}$ Jet Propulsion Laboratory, California Institute of Technology, Wrightwood, CA 92397, USA \\ ${ }^{2}$ Department of Physics and Astronomy, The University of Western Ontario, London, Canada \\ ${ }^{3}$ Royal Netherlands Meteorological Institute (KNMI), Bilthoven, the Netherlands \\ ${ }^{4}$ Meteoswiss, Payerne, Switzerland \\ ${ }^{5}$ Observatoire des Sciences de l'Univers de La Réunion, CNRS and Université de la Réunion (UMS3365), \\ Saint Denis de la Réunion, France \\ ${ }^{6}$ ISAC-CNR, Via Fosso del Cavaliere 100, 00133, Rome, Italy \\ Correspondence to: Thierry Leblanc (thierry.leblanc@jpl.nasa.gov)
}

Received: 6 April 2016 - Published in Atmos. Meas. Tech. Discuss.: 27 April 2016

Revised: 6 August 2016 - Accepted: 8 August 2016 - Published: 25 August 2016

\begin{abstract}
A standardized approach for the definition, propagation, and reporting of uncertainty in the temperature lidar data products contributing to the Network for the Detection for Atmospheric Composition Change (NDACC) database is proposed. One important aspect of the proposed approach is the ability to propagate all independent uncertainty components in parallel through the data processing chain. The individual uncertainty components are then combined together at the very last stage of processing to form the temperature combined standard uncertainty.

The identified uncertainty sources comprise major components such as signal detection, saturation correction, background noise extraction, temperature tie-on at the top of the profile, and absorption by ozone if working in the visible spectrum, as well as other components such as molecular extinction, the acceleration of gravity, and the molecular mass of air, whose magnitudes depend on the instrument, data processing algorithm, and altitude range of interest.

The expression of the individual uncertainty components and their step-by-step propagation through the temperature data processing chain are thoroughly estimated, taking into account the effect of vertical filtering and the merging of multiple channels. All sources of uncertainty except detection noise imply correlated terms in the vertical dimension,
\end{abstract}

which means that covariance terms must be taken into account when vertical filtering is applied and when temperature is integrated from the top of the profile. Quantitatively, the uncertainty budget is presented in a generic form (i.e., as a function of instrument performance and wavelength), so that any NDACC temperature lidar investigator can easily estimate the expected impact of individual uncertainty components in the case of their own instrument.

Using this standardized approach, an example of uncertainty budget is provided for the Jet Propulsion Laboratory (JPL) lidar at Mauna Loa Observatory, Hawai'i, which is typical of the NDACC temperature lidars transmitting at $355 \mathrm{~nm}$. The combined temperature uncertainty ranges between 0.1 and $1 \mathrm{~K}$ below $60 \mathrm{~km}$, with detection noise, saturation correction, and molecular extinction correction being the three dominant sources of uncertainty. Above $60 \mathrm{~km}$ and up to $10 \mathrm{~km}$ below the top of the profile, the total uncertainty increases exponentially from 1 to $10 \mathrm{~K}$ due to the combined effect of random noise and temperature tie-on. In the top $10 \mathrm{~km}$ of the profile, the accuracy of the profile mainly depends on that of the tie-on temperature. All other uncertainty components remain below $0.1 \mathrm{~K}$ throughout the entire profile $(15-$ $90 \mathrm{~km}$ ), except the background noise correction uncertainty, which peaks around $0.3-0.5 \mathrm{~K}$. It should be kept in mind that 
these quantitative estimates may be very different for other lidar instruments, depending on their altitude range and the wavelengths used.

\section{Introduction}

The present article is the last of three companion papers that provide a comprehensive description of recent recommendations made to the Network for Detection of Stratospheric Change (NDACC) lidar community for the standardization of vertical resolution and uncertainty in the NDACC lidar data processing algorithms. More than 20 lidar instruments contribute long-term measurements to NDACC, as well as to the validation of satellite or aircraft measurements. A wide range of methodologies and technologies is used for NDACC lidar instrumentation, which inherently raises the issue of consistency across the network, especially when using the lidar data to detect long-term trends, to perform intercomparisons and model or instrument validation, or when trying to ingest the data in assimilation models.

No comprehensive effort has been made until recently to facilitate a standardization of the definitions and approaches used in the NDACC lidar data processing algorithms. In 2011, an International Space Science Institute (ISSI) international team of experts (http://www.issibern.ch/aboutissi/ mission.html) (henceforth ISSI team) was formed with the objective of providing recommendations on the use of standardized definitions or approaches for vertical resolution and the treatment of uncertainty in the NDACC lidar retrievals (Leblanc et al., 2016a). Our first companion paper (Part 1) (Leblanc et al., 2016b) summarizes the recommendations made by the ISSI team for the use of standardized definitions of vertical resolution. Our second companion paper (Part 2) (Leblanc et al., 2016c) summarizes the definitions and approaches proposed by the ISSI team for a standardized treatment of uncertainty in the ozone differential absorption lidar (DIAL) retrievals. The present paper (Part 3) presents a work similar to that presented in our Part 2, but for the temperature lidar retrievals. The approach and recommendations described here apply to the density integration technique (Hauchecorne and Chanin, 1980), but not to the optimal estimation method (OEM) (Sica and Haefele, 2015) by which vertical resolution and uncertainties are computed implicitly. Some concepts described here and in our Part 2 companion paper may be used for the rotational Raman technique, but will not be discussed here. In the rest of this work, for brevity, every mention of "temperature lidar" will only refer to the retrieval of temperature using the density integration technique.

Middle atmospheric temperature profiles $(15-80 \mathrm{~km})$ have been measured by lidar for decades now using the density integration technique (e.g., Hauchecorne and Chanin, 1980; Keckhut et al., 1993, 2011). The corresponding tempera- ture uncertainty budgets, as reported in the literature, have typically included statistical noise (e.g., Hauchecorne and Chanin, 1980), and less frequently other components such as saturation ("pulse pile-up") (e.g., Leblanc et al., 1998), ozone absorption correction (Sica et al., 2001) or temperature initialization (Argall, 2007). Using synthetic lidar signals, Leblanc et al. (1998) provided a review of the most common error sources made in the lidar temperature retrievals. Intercomparison campaigns set up in the framework of NDACC have also contributed to the assessment of lidar measurement uncertainties (Keckhut et al., 2004).

In this paper, we propose a standardized and consistent approach for the introduction and propagation of the uncertainty components contributing to the full temperature uncertainty budget. Reference definitions on uncertainty are briefly reviewed in Sect. 2. Based on these definitions, a standardized measurement model for temperature lidars using the density integration technique is proposed in Sect. 3. Using this model, a complete formulation for the propagation of uncertainty through the temperature lidar algorithm is provided in Sect. 4. An example of an actual temperature uncertainty budget is then provided in Sect. 5 , followed by a brief summary and conclusion. The structure of the present paper and the fundamentals described in it are very similar to those presented in our Part 2 companion paper (Leblanc et al., 2016c), and therefore the readers will find frequent references to this companion paper, which provides more details on many aspects reviewed here. Ultimately, the reader should refer to the ISSI team report (Leblanc et al., 2016a) for more details on all aspects covered in the present article.

\section{Reference definitions}

Two metrological concepts, namely "measurement model" and "combined standard uncertainty", should be quickly introduced prior to proposing a standardized approach for the treatment of the temperature uncertainty for the NDACC lidars. It is strongly advised to refer to our Part 2 companion paper (Leblanc et al., 2016b), where these concepts are discussed in more detail, with key references to the metrological standards of the Bureau International des Poids et Mesures (BIPM) (JCGM 100, 2008; JCGM 200, 2008, 2012). Here we only provide a very brief overview.

\subsection{Measurement model}

For complex measurement techniques such as lidar, the retrieved temperature profile depends on multiple instrumental and physical parameters (see Sect. 3.2 thereafter). We therefore introduce the concept of measurement model, which is a "mathematical relation among all quantities known to be involved in a measurement" (VIM art. 2.48; JCGM 200, 2012). These quantities are referred to as the "input quantities", and the quantity derived from them is referred to as 
the "output quantity". A measurement model represents the mathematical architecture around which a standardized uncertainty budget can be built. The individual values $y$ of an output quantity $Y$ describing a measurement model that comprises multiple input quantities $x_{n}$ can be approximated to the first order of its Taylor-expanded form:

$y=f\left(x_{1}, x_{2}, \ldots, x_{N}\right)=y_{0}+\sum_{n=1}^{N} \frac{\partial y}{\partial x_{n}} x_{n}$.

The fully expanded form of this equation is provided in our Part 2 companion paper. Equation (1) is at the origin of the so-called "law of propagation of uncertainty" defined in the next paragraph.

\subsection{Combined standard uncertainty}

The definition of uncertainty recommended by the ISSI team for use by all NDACC lidar measurements is the combined standard uncertainty. Standard uncertainty is defined in article 2.30 of the VIM (JCGM 200, 2012) as "the measurement uncertainty expressed as a standard deviation". The true values of a model's input quantities $x_{n}$ are unknown, and can be assigned a standard uncertainty $u_{n}$ that characterizes their probability distribution. The output quantity's combined standard uncertainty $u_{y}$ is the "standard measurement uncertainty that is obtained using the individual standard uncertainties associated with the input quantities". The input quantities' uncertainty components can either be estimated by type A or type B evaluations. A type A standard uncertainty is obtained from a probability density function derived from an observed frequency distribution, while a type B standard uncertainty is obtained from an assumed probability density function based on best available knowledge. When two input quantities $x_{n}$ and $x_{m}$ are correlated (i.e., their correlation coefficient $r_{n m}$ is not equal to zero), their covariance must be taken into account. The combined standard uncertainty is equal to the positive square root of the combined variance obtained from all variance and covariance components using the law of propagation of uncertainty (art. 5.2 of the GUM; JCGM 100, 2008) which, when using the notation of Eq. (1), can be written as follows:

$$
\begin{aligned}
u_{y} & =\sqrt{\sum_{n=1}^{N} \sum_{m=1}^{N} \frac{\partial y}{\partial x_{n}} \frac{\partial y}{\partial x_{m}} \operatorname{cov}\left(x_{n}, x_{m}\right)} \\
& =\sqrt{\sum_{n=1}^{N}\left(\frac{\partial y}{\partial x_{n}}\right)^{2} u_{n}^{2}+2 \sum_{m=1}^{N-1} \sum_{n=m+1}^{N} \frac{\partial y}{\partial x_{n}} \frac{\partial y}{\partial x_{m}} r_{n m} u_{n} u_{\mathrm{m}}}
\end{aligned}
$$

Equations (1)-(2) as well as other expressions described in Sect. 2 of our Part 2 companion paper fully characterize a measurement model and the output quantity's combined standard uncertainty.

\section{Proposed measurement model for the NDACC temperature lidars}

In this section, a standardized lidar measurement model for the retrieval of temperature using the density integration technique is constructed. We start with the most general form of the lidar equation (Sect. 3.1), then we revert this equation (Sect. 3.2) with the assumptions that (1) the beam is vertical, (2) there is complete overlap between the beam and the telescope field of view, (3) the lidar receiver uses filters that are wide enough so that they are insensitive to the temperature dependence of the Raman spectrum, and (4) detection mode is photon-counting only (Sect. 3.3). The cases of analog detection and incomplete overlap are partially treated in the full ISSI team report (Leblanc et al., 2016a). The present approach implies the replacement of a single, complex temperature measurement model by the successive application of multiple, simpler measurement sub-models, which typically are specific transformations of the raw lidar signals. For each signal transformation, standard uncertainty can be evaluated in parallel for each independent uncertainty source. During the final data processing stage, all independent components are combined together to obtain the temperature combined standard uncertainty.

\subsection{Lidar equation}

As in most lidar applications, the fundamental equation at the source of the middle atmospheric temperature lidar retrieval using the density integration technique is the lidar equation (e.g., Hinkley, 1976). The equation describes the emission of light by a laser source, its backscatter at altitude $z$, its extinction and scattering along the laser beam path up and back, and its collection on a detector. One form of the lidar equation is expressed as

$$
\begin{aligned}
& P\left(z, \lambda_{1}, \lambda_{2}\right)= \\
& P_{\mathrm{L}}\left(\lambda_{1}\right) \frac{\eta\left(z, \lambda_{2}\right) \delta z}{\left(z-z_{\mathrm{L}}\right)^{2}} \tau_{\mathrm{UP}}\left(z, \lambda_{1}\right) \beta\left(z, \lambda_{1}, \lambda_{2}\right) \tau_{\mathrm{DOWN}}\left(z, \lambda_{2}\right),
\end{aligned}
$$

where

$-\lambda_{1}$ is the laser emission wavelength and $\lambda_{2}$ is the receiver detection wavelength;

- $P$ is the total number of photons collected at wavelength $\lambda_{2}$ on the lidar detector surface;

- $\delta z$ is the thickness of the backscattering layer sounded during the time interval $\delta t(\delta z=c \delta t / 2$, where $c$ is the speed of light);

- $P_{\mathrm{L}}$ is the number of photons emitted at the emission wavelength $\lambda_{1}$;

- $\eta$ is the optical efficiency of the receiving channel, including optical and spectral transmittance and geometric obstruction; 
- $z$ is the altitude of the backscattering layer;

$-z_{\mathrm{L}}$ is the altitude of the lidar (laser and receiver assumed to be at the same altitude);

- $\beta$ is the total backscatter coefficient (including particulate and molecular backscatter);

- $\tau_{\mathrm{UP}}$ is the atmospheric transmission integrated along the outgoing beam path between the lidar and the scattering altitude $z$, and is defined as

$\tau_{\mathrm{UP}}(z)=\exp$

$\left[-\int_{z_{\mathrm{L}}}^{z}\left(\sigma_{\mathrm{M}}\left(\lambda_{1}\right) N_{\mathrm{a}}\left(z^{\prime}\right)+\alpha_{\mathrm{P}}\left(z^{\prime}, \lambda_{1}\right)+\sum_{i} \sigma_{i}\left(z^{\prime}, \lambda_{1}\right) N_{i}\left(z^{\prime}\right)\right) \mathrm{d} z^{\prime}\right]$;

- $\tau_{\text {DOWN }}$ is the atmospheric transmission integrated along the returning beam path between the scattering altitude $z$ and the lidar receiver, and is defined as

$\tau_{\text {DOWN }}(z)=\exp$

$\left[-\int_{z_{\mathrm{L}}}^{z}\left(\sigma_{\mathrm{M}}\left(\lambda_{2}\right) N_{\mathrm{a}}\left(z^{\prime}\right)+\alpha_{\mathrm{P}}\left(z^{\prime}, \lambda_{2}\right)+\sum_{i} \sigma_{i}\left(z^{\prime}, \lambda_{2}\right) N_{i}\left(z^{\prime}\right)\right) \mathrm{d} z^{\prime}\right]$,

where $\sigma_{\mathrm{M}}$ is the molecular extinction cross section due to Rayleigh scattering (Strutt, 1899) (hereafter called "Rayleigh cross section" for brevity), $N_{\mathrm{a}}$ is the air number density, $\alpha_{\mathrm{P}}$ is the particulate extinction coefficient, $\sigma_{i}$ is the absorption cross section of absorbing constituent $i$, and $N_{i}$ is the number density of absorbing constituent $i$. For altitudes between the ground and $90 \mathrm{~km}$, the Rayleigh cross sections can be considered constant with altitude, and therefore depend only on wavelength. The absorption cross sections, however, are in most cases temperature-dependent, and should be taken as a function of both altitude and wavelength. Temperature is retrieved by inverting Eq. (3) with respect to the backscatter term $\beta$.

\subsection{Inversion of the lidar equation for temperature retrieval}

In the absence of particulate backscatter, the backscatter coefficient $\beta$, and therefore the lidar signal collected on the detector, is proportional to the air number density. Temperature is then calculated by vertically integrating air number density, assuming hydrostatic balance and assuming that the air is an ideal gas (Hauchecorne and Chanin, 1980). This inversion technique works for both elastic scattering (Rayleigh backscatter by the air molecules) and inelastic scattering (normally, using vibrational Raman backscatter by the nitrogen molecules) (Strauch et al., 1971; Gross et al., 1997). For either technique, we can write a generic form of the backscatter coefficient as a function of air number density $N_{\mathrm{a}}$ :

$\beta(z)=\sigma_{\beta} N_{\mathrm{a}}(z)$.
Table 1. List of most commonly used backscatter temperature lidar wavelengths.

\begin{tabular}{|c|c|c|c|c|}
\hline $\begin{array}{l}\lambda_{1} \\
(\mathrm{~nm})\end{array}$ & $\begin{array}{l}\lambda_{2} \\
(\mathrm{~nm})\end{array}$ & $\begin{array}{l}\text { Backscatter } \\
\text { technique }\end{array}$ & $\begin{array}{l}\text { Domain of } \\
\text { validity }\end{array}$ & $\begin{array}{l}\text { Light source details } \\
\left(\lambda_{1}\right)\end{array}$ \\
\hline 353 & 353 & Rayleigh & $30<z<100 \mathrm{~km}$ & $\begin{array}{l}\text { Excimer XeCl } \\
308 \text { nm Raman-shifted }\end{array}$ \\
\hline 353 & 385 & $\mathrm{~N}_{2}$ Raman & $10<z<40 \mathrm{~km}$ & $\begin{array}{l}\text { Excimer XeCl } \\
308 \text { nm Raman-shifted }\end{array}$ \\
\hline 355 & 355 & Rayleigh & $30<z<100 \mathrm{~km}$ & $\begin{array}{l}\text { Nd:YAG tripled } \\
355 \mathrm{~nm} \text { non-shifted }\end{array}$ \\
\hline 355 & 387 & $\mathrm{~N}_{2}$ Raman & $10<z<40 \mathrm{~km}$ & $\begin{array}{l}\text { Nd:YAG tripled } \\
355 \mathrm{~nm} \text { non-shifted }\end{array}$ \\
\hline 532 & 532 & Rayleigh & $30<z<110 \mathrm{~km}$ & $\begin{array}{l}\text { Nd:YAG doubled } \\
532 \mathrm{~nm} \text { non-shifted }\end{array}$ \\
\hline 532 & 608 & $\mathrm{~N}_{2}$ Raman & $10<z<40 \mathrm{~km}$ & $\begin{array}{l}\text { Nd:YAG doubled } \\
532 \mathrm{~nm} \text { non-shifted }\end{array}$ \\
\hline
\end{tabular}

For Rayleigh backscatter, the effective cross section $\sigma_{\beta}$ is the molecular (Rayleigh) scattering cross section at the emission wavelength $\lambda_{1}$ :

$\sigma_{\beta}=\sigma_{\mathrm{M}}\left(\lambda_{1}\right)$.

For Raman backscatter, the effective cross section $\sigma_{\beta}$ is the vibrational Raman scattering cross section of a well-mixed gas (typically nitrogen) at the Raman-shifted wavelength $\lambda_{2}$, multiplied by the mixing ratio of the well-mixed gas (e.g., 0.781 for nitrogen):

$\sigma_{\beta}=0.781 \sigma_{N 2}\left(\lambda_{1}, \lambda_{2}\right)$.

Substituting into the lidar equation Eq. (3), we obtain an expression of air number density as a function of the backscatter lidar signal:

$N_{\mathrm{a}}(z)=\frac{P\left(z, \lambda_{1}, \lambda_{2}\right)\left(z-z_{\mathrm{L}}\right)^{2}}{\sigma_{\beta} \eta\left(z, \lambda_{1}, \lambda_{2}\right) \delta z P_{\mathrm{L}}\left(\lambda_{1}\right) \tau_{\mathrm{UP}}\left(z, \lambda_{1}\right) \tau_{\mathrm{DOWN}}\left(z, \lambda_{2}\right)}$.

A temperature profile is then calculated, assuming hydrostatic balance, and assuming that the air is an ideal gas with a constant mean molecular mass:

$T(z-\delta z)=\frac{N_{\mathrm{a}}(z)}{N_{\mathrm{a}}(z-\delta z)} T(z)+\frac{M_{\mathrm{a}}}{R_{\mathrm{a}} N_{\mathrm{a}}(z-\delta z)} \overline{N_{\mathrm{a}}}(z) \bar{g}(z) \delta z$,

where $T$ is the retrieved temperature, $M_{\mathrm{a}}$ is the molecular mass of dry air, $R_{\mathrm{a}}$ is the ideal gas constant, and $g$ is the acceleration of gravity. The horizontal bar above $N_{\mathrm{a}}$ and $g$ represents the average value of $N_{\mathrm{a}}$ and $g$ between $z$ and $z-\delta z$. An essential aspect of the method is that all altitudeindependent terms (e.g., Rayleigh cross section, lidar receiver efficiency) cancel out when computing the ratio of air number density at altitudes $z$ and $z-\delta z$.

A list of the most commonly used wavelengths is compiled in Table 1.

\subsection{Actual temperature measurement model proposed for standardized use within NDACC}

The actual temperature measurement model proposed for a standardized NDACC lidar temperature uncertainty budget 
is a real-world version of the theoretical model described in the previous paragraph after considering the technical limitations owing to the design, setup, and operation of a real lidar instrument.

First, several assumptions about the properties of the atmosphere must be made to help reduce the complexity of our proposed measurement model. Specifically, uncertainty components associated with particulate extinction and backscatter will not be considered here. For Rayleigh backscatter channels, the bottom of the retrieved temperature profile is typically at $25-30 \mathrm{~km}$, where the atmosphere is normally "clean". Particulate matter contribution may occasionally be significant below $35 \mathrm{~km}$ in the presence of heavy stratospheric volcanic loading (e.g., Mount Pinatubo eruption in 1991). In addition, the effect of multiple scattering above high clouds (e.g., Reichardt and Reichardt, 2006) is not considered here.

When present, the amount and physical properties of the particulate matter can be highly variable from site to site and from time to time, and very difficult to estimate. The standardized treatment of these uncertainty components is therefore too complex to be included in the present work. However, it should be considered in a dedicated study using leverage from past work, for example work performed within the EARLINET project (D'Amico et al., 2015; Mattis et al., 2016).

Secondly, the number of photons collected on the lidar detectors $P$, as it appears in Eq. (9), is different from the actual raw lidar signals recorded in the data files. Signal corrections and numerical transformations related to the instrumentation are necessary. The backscattered signal is indeed altered by sky and electronic background noise, efficiency loss, signal saturation in photon-counting mode (pulse pileup), and sometimes other nonlinear effects that must be taken into account. Because of the wide range of lidar instrumentation, providing a unique expression for the parametrization of these effects is very challenging. Here we consider a few special cases representing the largest fraction of currently operated NDACC lidar systems.

In order to transition from a theoretical to a real temperature measurement model, the following assumptions and transformations will be made.

1. For each lidar receiver channel, the actual raw signal $R$ recorded in the data files is represented by a vector of discretized values rather than a continuous function of altitude range:

$z \rightarrow z(k)$ and $R(z) \rightarrow R(k)$ for $k=1, n k$.

2. Only channels operating in photon-counting mode are considered in this measurement model. The estimation of the uncertainty due to analog-to-digital signal conversion is instrument-dependent, and therefore no meaningful standardized recommendations can be made. However, for some systems, analog signal count- ing statistics were reported to be consistent with a Poisson distribution (Whiteman et al., 2006), and therefore many aspects of the treatment of uncertainty owing to detection noise described in this manuscript are likely to apply to analog-to-digital converted signals. An example of the treatment of the analog-to-detection uncertainty is provided in the ISSI team report (Leblanc et al., 2016a)

3. For each lidar receiver channel, the actual raw signal recorded in the data files comprises an altitudedependent signal resulting from the laser light backscattered in the atmosphere, a constant (typically small) noise coming from the sky background light, and timedependent (typically small) noise generated within the electronics (dark current and signal-induced noise). The noise components can be parametrized by either a constant, linear, or nonlinear function of altitude range.

4. In photon-counting mode, signals of large magnitude are not recorded linearly in the data files. Signal saturation or a pulse pile-up effect occurs because of the inability of the counting electronics to discriminate a very large number of photon counts reaching the detector in time (e.g., Müller, 1973; Donovan et al., 1993). In the present work, we describe the common case of non-paralyzable photon-counting systems, which allows for an analytical correction of the pulse pile-up effect (Müller, 1973).

Given conditions (1) through (4), the photon counts $P$ reaching the detector of a given channel can be expressed as a function of the discretized raw signal $R$ recorded in the data files at altitude $z(k)$ :

$P(k)=\frac{R(k)}{1-\tau \frac{c}{2 \delta z L} R(k)}-B(k)$,

where $B$ is the sum of sky and electronic background noise, $\tau$ is the photon-counting hardware dead time characterizing the pulse pile-up effect (sometimes called resolving time), $c$ is the speed of light, and $L$ is the number of laser pulses for which the signal was actually recorded in the data files.

5. We then correct the signal for all known altitudedependent factors according to Eq. (9). For a given channel operating at the emission wavelength $\lambda_{1}$ and detection wavelength $\lambda_{2}\left(\lambda_{1}\right.$ and $\lambda_{2}$ are identical for Rayleigh backscatter channels), we then define $N$ as the lidar-measured relative number density, which can be written as a function of the saturation-background- 
corrected signal $P$ :

$$
\begin{aligned}
& N(k)=\frac{\left(z(k)-z_{\mathrm{L}}\right)^{2}}{\eta(k)} P(k) \exp \\
& \left(\sum_{k^{\prime}=0}^{k}\left(\left(\sigma_{\mathrm{M} \_1}+\sigma_{\mathrm{M} \_2}\right) N_{\mathrm{a}}\left(k^{\prime}\right)+\sum_{\mathrm{ig}}\left(\sigma_{\mathrm{ig} \_1}\left(k^{\prime}\right)+\sigma_{\mathrm{ig} \_2}\left(k^{\prime}\right)\right) N_{\mathrm{ig}}\left(k^{\prime}\right)\right) \delta z\right) .
\end{aligned}
$$

In this transformation, the efficiency factor $\eta$ does not have to be known in an absolute manner, but only its variation with altitude range does. Furthermore, if we assume that there is full overlap between the beam and the telescope field of view, then this factor is constant with altitude and does not need to be included at all. The subscripts $\mathrm{M}$ and ig refer to the Rayleigh cross sections and absorption cross sections of the interfering gases, respectively. The subscript extensions 1 and 2 refer to the emitted $\left(\lambda_{1}\right)$ and received wavelengths $\left(\lambda_{2}\right)$, respectively.

With the assumption of full overlap, the lidar-measured relative number density differs from the air number density only by a constant multiplication factor, and therefore does not need to include any of the constant terms with altitude found in the lidar equation as these terms cancel out in the temperature integration process (which implies the ratio of density at two consecutive altitudes).

6. Starting from the top of the profile $z\left(k_{\mathrm{TOP}}\right)$ where temperature is initialized using an ancillary temperature measurement $T_{\mathrm{a}}\left(k_{\mathrm{TOP}}\right)$ (procedure called temperature "tie-on"), the complete temperature profile can be retrieved integrating downward using lidar-measured relative number density. The real-world version of Eq. (10) becomes

$T(k)=\frac{N\left(k_{\mathrm{TOP}}\right)}{N(k)} T_{\mathrm{a}}\left(k_{\mathrm{TOP}}\right)+\frac{M_{\mathrm{a}} \delta z}{R_{\mathrm{a}} N(k)} S(k)$,

where $S(k)$ is the discretized version of the summation term in Eq. (9):

$S(k)=\sum_{k^{\prime}=k}^{k \mathrm{TOP}-1} \bar{N}\left(k^{\prime}\right) \bar{g}\left(k^{\prime}\right)$.

Like in Eq. (10), the horizontal bar above $N$ and $g$ denotes the mean value of $N$ and $g$ in the vertical layer comprised between $z\left(k^{\prime}\right)$ and $z\left(k^{\prime}+1\right)$. The lidar-derived relative density $N$ can be approximated by an exponential function of altitude range, and the layer-averaged density is computed using its geometric mean:

$\bar{N}\left(k^{\prime}\right)=\sqrt{N\left(k^{\prime}\right) N\left(k^{\prime}+1\right)}$.

The Earth's gravity field is three-dimensional but its variation with longitude is so small that it can only be approximated by a function of latitude and altitude. For small vertical increments, the variation of $g$ with height is nearly linear, and its layer-averaged value can be expressed as a function of the height $h$ above the reference ellipsoid averaged between $z\left(k^{\prime}\right)$ and $z\left(k^{\prime}+1\right)$ :

$\bar{g}\left(k^{\prime}\right)=g_{0}\left(1+g_{1} \bar{h}\left(k^{\prime}\right)+g_{2} \bar{h}^{2}\left(k^{\prime}\right)\right)$.

The height above the reference ellipsoid averaged between $z\left(k^{\prime}\right)$ and $z\left(k^{\prime}+1\right)$ takes the following form:

$\bar{h}\left(k^{\prime}\right)=\frac{1}{2}\left(h\left(k^{\prime}\right)+h\left(k^{\prime}+1\right)\right)$.

The constants $g_{0}, g_{1}$, and $g_{2}$ in Eq. (16) relate to the Earth's geometry and to the geodetic latitude of the lidar site. The derivation of the constants $g_{0}, g_{1}$, and $g_{2}$ following the World Geodetic System (NIMA-WGS 1984, 2000) is provided in Sect. 3.5 of the ISSI team report (Leblanc et al., 2016a).

7. Optional smoothing: As in any real physical measurement, detection noise induces undesired high-frequency noise in the raw lidar signals. This noise can be reduced by digitally filtering the signals and/or the retrieved temperature profiles. The filtering process impacts the propagation of uncertainties, and therefore should be included in the measurement model. When filtering is applied to the lidar signal (i.e., before temperature is computed), the signal's exponential decrease with altitude must be taken into account. For a given altitude $z(k)$, the filtering process in this case therefore consists of convolving a set of filter coefficients $c_{\mathrm{p}}$ with the logarithm of the unsmoothed signal $s_{\mathrm{u}}\left(s_{\mathrm{u}}=R\right.$ or $s_{\mathrm{u}}=P$ or $\left.s_{\mathrm{u}}=N\right)$ to obtain a smoothed signal $s_{\mathrm{m}}$ following the expression

$s_{\mathrm{m}}(k)=\exp \left(\sum_{\mathrm{p}=-n}^{n} c_{\mathrm{p}}(k) \log \left(s_{\mathrm{u}}(k+p)\right)\right)$.

When vertical filtering is applied to the retrieved temperature profile, the filtering process at each individual altitude $z(k)$ consists of convolving the filter coefficients $c_{\mathrm{p}}$ with the unsmoothed temperature $T$ to obtain a smoothed temperature $T_{\mathrm{m}}$, following the expression

$T_{\mathrm{m}}(k)=\sum_{\mathrm{p}=-n}^{n} c_{\mathrm{p}}(k) T(k+p)$.

In Eqs. (17)-(18), the filter coefficients should be symmetric $\left(c_{\mathrm{p}}=c_{-\mathrm{p}}\right.$ for all $\left.p\right)$ to achieve proper smoothing. Their number and values determine which noise frequencies will be reduced most. A review of digital filtering and recommendations for the use of standardized vertical resolution definitions are provided in our Part 1 companion paper (Leblanc et al., 2016a). 
8. Optional merging: Temperature lidar instruments are usually designed with multiple channels of varying signal intensity to maximize the overall altitude range of the profile. Here, the propagation of uncertainty is considered for two channels being merged to form a single profile. This profile covering the entire useful range of the instrument is typically obtained by combining the most accurate overlapping sections of the profiles retrieved from individual channels. Merging individual intensity channels into a single profile can be done either during lidar signal processing or after the temperature is calculated for each individual channel. The thickness of the transition region can vary from a few meters to a few kilometers, depending on the instrument and on the intensity of the channels considered.

When the merging procedure is applied before the temperature profile is computed, it can be done on the raw signals $(s=R)$, the saturation-background corrected signals $(s=P)$, or the lidar-derived relative density $(s=N)$. The signals of the channels that are to be combined are of different magnitude, and signal normalization of one channel with respect to the other is necessary before combining the channels ( $\kappa$ being the scaling factor). Since the signals' decrease with altitude is nearly exponential, the merging procedure should be done on the logarithm of the signal rather than the signal itself. Considering a low-intensity channel $i_{\mathrm{L}}$ and a high-intensity channel $i_{\mathrm{H}}$, and assuming that the transition region's bottom and top altitudes are $z\left(k_{1}\right)$ and $z\left(k_{2}\right)$ respectively, the merged signal $s_{\mathrm{M}}$ at any altitude bin $k$ comprised between $k_{1}$ and $k_{2}$ is typically obtained by computing a weighted average of the $\log$-signal values $s_{\mathrm{m}}$ (or $s$ if unsmoothed) for each range and at the same altitude bin:

$s_{\mathrm{M}}(k)=\exp \left(w(k) \log \left(s\left(k, i_{\mathrm{L}}\right)\right)+(1-w(k)) \log \left(\kappa s\left(k, i_{\mathrm{H}}\right)\right)\right)$

$k_{1} \leq k \leq k_{2}$ and $0 \leq w(k) \leq 1$.

When the merging procedure is applied to the retrieved temperature profiles, the merged temperature $T_{\mathrm{M}}$ at any altitude bin $k$ comprised between $k_{1}$ and $k_{2}$ is typically obtained by computing a weighted average of the temperature values $T_{\mathrm{m}}$ (or $T$ if unsmoothed) retrieved for each range at the same altitude bin:

$T_{\mathrm{M}}(k)=w(k) T_{\mathrm{m}}\left(k, i_{\mathrm{L}}\right)+(1-w(k)) T_{\mathrm{m}}\left(k, i_{\mathrm{H}}\right) k_{1} \leq k \leq k_{2}$

and $0 \leq w(k) \leq 1$.

Equations (11)-(21) constitute our proposed standardized temperature measurement model. The output quantity is temperature (left-hand side of Eq. 13), while the input quantities are all the variables introduced on the right-hand side of Eqs. (12)-(17). The input quantities' standard uncertainty must be introduced, then propagated through the temperature measurement model, and then combined to produce a temperature combined standard uncertainty profile.
Based on Eq. (11), the instrumentation-related input quantities to consider in the NDACC-lidar standardized temperature uncertainty budget are as follows:

1. detection noise inherent to photon-counting signal detection;

2. saturation (pulse pile-up) correction parameters (typically, photon counters' dead time $\tau$ );

3. background noise extraction parameters (typically, fitting parameters for function $B$ ).

Based on Eqs. (12)-(16), the additional input quantities to consider in the NDACC-lidar standardized temperature uncertainty budget are as follows:

4. Rayleigh extinction cross sections $\sigma_{\mathrm{M}}$;

5. ancillary air number density profile $N_{\mathrm{a}}$ (or temperature $T_{\mathrm{a}}$ and pressure $p_{\mathrm{a}}$ profiles);

6. absorption cross sections of the interfering gases $\sigma_{\text {ig }}$;

7. number density profiles $N_{\text {ig }}$ (or mixing ratio profile $q_{\mathrm{ig}}$ ) of the interfering species;

8. acceleration of gravity $g$;

9. the molecular mass of air $M_{\mathrm{a}}$;

10. ancillary air temperature for tie-on at the top of the profile $T_{\mathrm{a}}\left(k_{\mathrm{TOP}}\right)$.

The above input quantities are not listed in order of significance, but instead, in the order they are introduced into the lidar temperature model. Quantitatively, the most significant uncertainty components are typically detection noise (1) and temperature tie-on (10) at the top of the profile, and saturation correction (2) and molecular extinction (4 and 5) at the bottom of the profile. The interfering gases (ig) to consider in practice are ozone and $\mathrm{NO}_{2}$. Because of either very low concentrations or very low values of their absorption cross sections, no other atmospheric gases or molecules are known to interfere with the temperature retrieval. The impact of absorption by ozone on the temperature retrieval is very small $(<0.1 \mathrm{~K})$ if working at wavelengths near the ozone minimum absorption region (e.g., 355, $387 \mathrm{~nm}$ ), but can account for up to $1 \mathrm{~K}$ error if neglected when working in the Chappuis band (e.g., 532 and $607 \mathrm{~nm}$ ). Conversely, absorption by $\mathrm{NO}_{2}$ is very small for temperature retrievals in the Chappuis band, but can account for up to a $0.2 \mathrm{~K}$ error if neglected at 355 and $387 \mathrm{~nm}$.

The uncertainty contribution of the acceleration of gravity is very small $(<0.1 \mathrm{~K})$ provided the formulation of gravity is altitude-dependent (e.g., Eq. 16) (Lemoine et al., 1998). In the upper mesosphere, the change in the air major species' mixing ratio induces a change in altitude of the air molecular mass and Rayleigh scattering cross sections. However, the 
induced changes remain below $0.1 \mathrm{~K}$ below $90 \mathrm{~km}$, which is much less than the expected uncertainty owing to the other sources such as detection noise and tie-on temperature uncertainty (Argall, 2007). For temperature profiles reaching $100 \mathrm{~km}$ or higher, the change of the molecular mass of air with altitude should be taken into account.

When the receiver field of view and the laser beam are known to not fully overlap, an additional instrumentationrelated uncertainty component must be introduced to take into account the overlap correction (altitude-dependent term $\eta$ in Eq. 12). Additionally, if the lidar receiver uses very narrow filters (typically narrower than $0.7 \mathrm{~nm}$ ), another instrumentation-related uncertainty component must be introduced to take into account the temperature dependence of the Raman backscatter cross sections (causing again the term $\eta$ in Eq. (12) to be altitude-dependent). Because the overlap function and the filter width and position are strongly instrument-dependent, a standardized approach for the treatment of those uncertainty components cannot be proposed here (beyond the scope of this paper). In the rest of this work, we will therefore assume full overlap and wide-enough filters to prevent an altitude dependence of the lidar transmission function.

The exact altitude of each data bin $k$ can be determined experimentally, for example by tracking the exact position in the data stream of the laser beam backscattering off the laser room hatch (assuming that the receiver and the transmission of the laser beam in the atmosphere are located in the same room). The time (i.e., altitude) resolution of today's lidar data acquisition hardware is very high (of the order of nanoseconds, i.e., a few meters). The exact altitude of the lidar instrument can also be determined to a precision better than $1 \mathrm{~m}$ using today's standard geopositioning methods. For well-designed and well-validated lidar instruments, there is therefore no uncertainty associated with the determination of altitude, and therefore no uncertainty associated with the range correction $\left(z^{2}\right)$ term in Eq. (12).

Finally, in our proposed measurement model, uncertainties associated with fundamental physical constants are neither introduced nor propagated. As described in our Part 2 companion paper, it is proposed to use fundamental physical constants truncated at a decimal level where no change occurs to its value if adding or subtracting its uncertainty. It is also recommended that the values reported by the International Council for Science (ICSU) Committee on Data for Science and Technology (CODATA, http://www.codata. org/), endorsed by the BIPM (Mohr et al., 2008), are used. For example, the molar gas constant value $R_{\mathrm{a}}$ reported by the CODATA is $8.3144621 \mathrm{Jmol}^{-1} \mathrm{~K}^{-1}$, with an uncertainty of $0.0000075 \mathrm{Jmol}^{-1} \mathrm{~K}^{-1}$. If we truncate to the value of $8.3145 \mathrm{Jmol}^{-1} \mathrm{~K}^{-1}$, adding or subtracting its uncertainty does not modify the truncated value, and we therefore consider this value as "exact" (i.e., no uncertainty to be propagated). Note that if the uncertainty of a fundamental constant is of a similar order of magnitude as that of some other un- certainty components already identified, then this constant must be included among the input quantities and its uncertainty should be taken into account and propagated just like all other input quantities.

\section{Proposed formulation for the propagation of uncertainty through the lidar temperature retrieval}

In the present section, the law of propagation of uncertainty (Eq. 2) is used to propagate the uncertainty components introduced in our proposed standardized measurement model (previous section). The reader should refer to Sect. 2 of our Part 2 companion paper or to the ISSI team report (Leblanc et al., 2016a) for more details on the conditions of validity of some of the expressions proposed hereafter.

In order to distinguish between the uncertainty source and the quantity for which the uncertainty is calculated, a standardized notation is used throughout this section. Each new equation introduced represents a measurement sub-model that yields an output quantity $Y$, with individual uncertainty components $u_{Y(X i)}$ owing to the uncertainty source $X_{i}$. Furthermore, each introduced component $u_{Y(X i)}$ is assumed to be independent of the other components $u_{Y(X j)}(j \neq i)$, thus allowing a full description of their covariance matrix in the altitude dimension, and therefore a propagation in parallel with the other independent components throughout signal processing.

\subsection{Uncertainty owing to detection noise}

Signal detection uncertainty is introduced at the detection level, where the signal is recorded in the data files (raw signal $R$ ). It is derived from Poisson statistics associated with the probability of detection of a repeated random event (type A uncertainty estimation). Using the subscript (DET) for detection noise, the uncertainty in the raw (summed) signal $R$ owing to detection noise expressed for each altitude bin $k$ and for a single temperature channel is written as follows:

$u_{R(\mathrm{DET})}(k)=\sqrt{R(k)}$.

There is no correlation between any of the samples considered as this uncertainty component is owed to purely random effects (signal detection). It is propagated to the retrieved temperature profile by systematically assigning the individual input quantities covariance matrix's non-diagonal terms to zero. Assuming non-paralyzable photon-counting hardware, this uncertainty component is therefore propagated to the saturation and background-noise-corrected signal $P$ by applying Eq. (2) with no covariance terms to the signal transformation Eq. (11):

$u_{P(\mathrm{DET})}(k)=\left(\frac{P(k)}{R(k)}\right)^{2} \sqrt{R(k)}$. 
This uncertainty component is then propagated to the lidarderived relative density $N$ by applying Eq. (2) to the signal transformation Eq. (12):

$u_{N(\mathrm{DET})}(k)=\frac{N(k)}{P(k)} u_{P(\mathrm{DET})}(k)$.

Next, it is propagated through Eq. (13), assuming that the signals are uncorrelated between two consecutive altitudes. Applying Eq. (2) to the signal transformation Eq. (15) yields

$u_{\bar{N}(\mathrm{DET})}\left(k^{\prime}\right)=$

$\frac{1}{2} \sqrt{\frac{N\left(k^{\prime}+1\right)}{N\left(k^{\prime}\right)} u_{N(\mathrm{DET})}^{2}\left(k^{\prime}\right)+\frac{N\left(k^{\prime}\right)}{N\left(k^{\prime}+1\right)} u_{N(\mathrm{DET})}^{2}\left(k^{\prime}+1\right) .}$

The detection noise uncertainty then needs to be propagated to the sum $S$ defined in Eq. (14). This sum involves correlated terms as two consecutive terms contain two occurrences of the same values $\left(k^{\prime}\right.$ and $k^{\prime}+1$ first level, then $k^{\prime}+1$ and $k^{\prime}+2$ next level, etc.). The application of Eqs. (2) to (14) in its most general sense yields

$u_{S(\mathrm{DET})}(k)=$

$\sqrt{\sum_{k^{\prime}=k}^{k \mathrm{TOP}-1} \bar{g}^{2}\left(k^{\prime}\right) u_{\bar{N}(\mathrm{DET})}^{2}\left(k^{\prime}\right)+2 \sum_{k^{\prime}=k}^{k \mathrm{TOP}-2} \sum_{k^{\prime \prime}=k^{\prime}}^{K T O P-1} g\left(k^{\prime}\right) g\left(k^{\prime \prime}\right) u_{\bar{N}(\mathrm{DET})}\left(k^{\prime}\right) u_{\bar{N}(\mathrm{DET})}\left(k^{\prime \prime}\right) r_{k^{\prime} k^{\prime \prime}}}$.

The correlation coefficients $r_{k^{\prime}} k^{\prime \prime}$ between the terms $\bar{N}\left(k^{\prime}\right)$ and $\bar{N}\left(k^{\prime \prime}\right)$ are not strictly known. However, with the realistic assumption that the values of two consecutive terms are almost equal (i.e., $N$ values, $g$ values, and $u_{N \text { (DET) }}$ values), an approximation of Eq. (23) can be written as follows:

$u_{S(\mathrm{DET})}(k)=\sqrt{2 \sum_{k^{\prime}=k}^{k \mathrm{TOP}-1} \bar{g}^{2}\left(k^{\prime}\right) u_{\bar{N}(\mathrm{DET})}^{2}\left(k^{\prime}\right) .}$

This expression is different from an expression assuming that all terms are independent (it is a factor of $\sqrt{2}$ larger), and it is also different from an expression assuming that all the terms are fully correlated (the weighed sum of all individual uncertainties). Though it differs from the theoretical expression, its magnitude once propagated to temperature is significantly smaller than the magnitude of the other terms contributing to temperature uncertainty owing to detection noise (see Eq. (25) below). For more accurate estimates of $u_{S(\mathrm{DET})}$, a full quantification of the correlation coefficients $r_{k^{\prime} k^{\prime \prime}}$ is required. The value of those coefficients depends on the lidar signal magnitude, the lidar sampling resolution, and the amount of vertical smoothing applied. For vertically unsmoothed signals, a simple parametrization of altitude can be used, starting at the value of 1 at the tie-on altitude, and decreasing exponentially to 0 several kilometers below. For vertically smoothed signals, the parametrization has to take into account the type of smoothing filter used and the number of filter coefficients as a function of altitude. The parameters of the correlation coefficients' altitude-dependent function can be determined by running Monte Carlo experiments, assuming repeatable behavior of the actual lidar signals considered.

The temperature uncertainty owing to detection noise $u_{T \text { (DET) }}$ is finally computed by applying Eq. (2) to the density integration Eq. (13):

$$
\begin{aligned}
& u_{T(\mathrm{DET})}(k)=\frac{1}{N(k) T(k)} \\
& \sqrt{T^{2}(k) u_{N(\mathrm{DET})}^{2}(k)+T_{\mathrm{a}}^{2}\left(k_{\mathrm{TOP}}\right) u_{N(\mathrm{DET})}^{2}\left(k_{\mathrm{TOP}}\right)+\left(\frac{M_{\mathrm{a}} \delta z}{R_{\mathrm{a}}}\right)^{2} u_{S(\mathrm{DET})}^{2}(k)} .
\end{aligned}
$$

The third term under the square root is much smaller than the first and second terms, typically by an order of magnitude or more. As a result, the inclusion or omission of the factor $\sqrt{2}$ in Eq. (24) has almost no impact on the actual temperature uncertainty owing to detection noise. The temperature uncertainty owing to detection noise, as defined by Eq. (25), can be of any order of magnitude, depending on altitude and lidar performance and/or specification. Figure 1 shows this order of magnitude as a function of signal magnitude (left) and altitude (right) for a wide range of lidar specifications. A channel performance is defined here for a given sampling resolution as the altitude at which the signal count rate is $1 \mathrm{MHz}$. Using such generic representation allows the identification of a family of curves, all of which have the same $e$-folding rate with altitude and signal magnitude. This way, the actual order of magnitude of the temperature uncertainty can be inferred for any lidar system of specific performance. Not surprisingly, this uncertainty component's $e$-folding rate is approximately $14 \mathrm{~km}$ (black arrow on the right plot), which corresponds to the square root of the $7 \mathrm{~km} e$-folding rate of air number density. The results in Fig. 1 are shown for a $120 \mathrm{~min}$ integration time and $50 \mathrm{~Hz}$ laser repetition rate. For an integration time that is 4 times shorter (30 min), all curves would shift to the right by a factor of 2 . For a integration time that is 4 times longer ( $8 \mathrm{~h}$ ), all curves would shift to the left by a factor of 2 .

\subsection{Uncertainty owing to saturation (pulse pile-up) correction}

The uncertainty component owing to saturation correction depends on the hardware's dead time $\tau$ and its uncertainty $u_{\tau}$, which are typically known from the technical specifications provided by the hardware manufacturer (type B estimation). This uncertainty component is introduced where the signal is recorded in the data files (raw signal $R$ ). Using the subscript (SAT) for saturation, the saturation correction uncertainty propagated to the saturation and background-noisecorrected signal $P$ is obtained by applying Eq. (2) to the signal transformation Eq. (11):

$u_{P(\mathrm{SAT})}(k)=\frac{2 \delta z}{c L} P^{2}(k) u_{\tau}$.

Just like the detection noise component, the saturation correction uncertainty component is propagated to the lidar- 

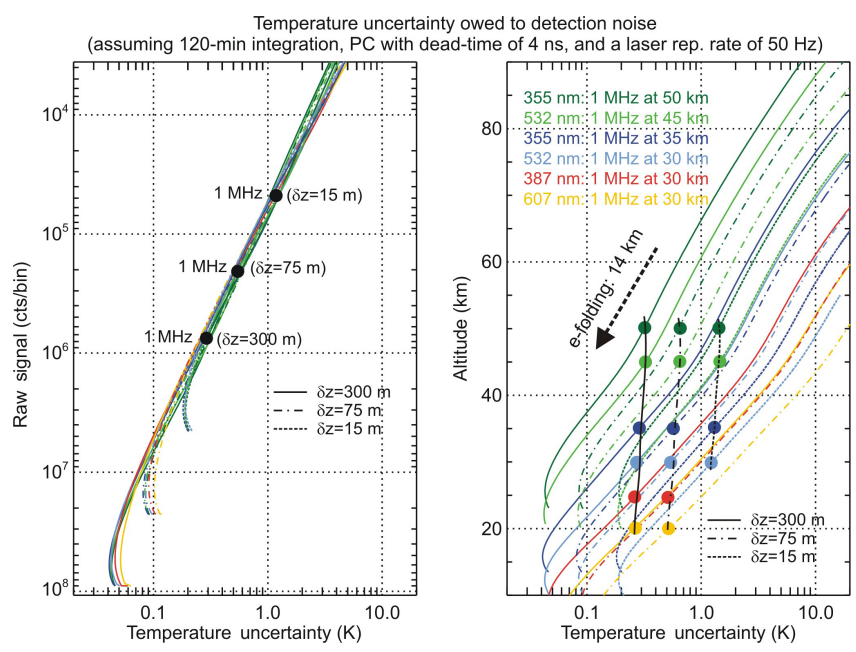

Figure 1. Temperature uncertainty owing to detection noise as a function of lidar signal magnitude (left) and altitude (right) for a variety of lidar performance configurations, specifically, two different signal strengths $(1 \mathrm{MHz}$ in the upper stratosphere and $1 \mathrm{MHz}$ in the lower stratosphere), two different emission wavelengths (ultraviolet and green), three different vertical samplings $(15,75$, and $300 \mathrm{~m}$ ), and two types of backscatter (Rayleigh and Raman). The solid circles indicate the location of the $1 \mathrm{MHz}$ signal count rate for a specific channel.

derived relative density $N$ by applying Eq. (2) to the signal transformation Eq. (12):

$u_{N(\mathrm{SAT})}(k)=\frac{N(k)}{P(k)} u_{P(\mathrm{SAT})}(k)$.

The saturation correction is applied to the lidar signals consistently at all altitudes. Its uncertainty is therefore propagated through Eq. (13), assuming full correlation between two consecutive altitudes $z\left(k^{\prime}\right)$ and $z\left(k^{\prime}+1\right)$. In these conditions, applying Eq. (2) to the signal transformation Eq. (15) yields

$$
\begin{aligned}
u_{\bar{N}(\mathrm{SAT})}\left(k^{\prime}\right) & =\frac{\bar{N}\left(k^{\prime}\right)}{2} \\
& \left(\frac{u_{N(\mathrm{SAT})}\left(k^{\prime}\right)}{N\left(k^{\prime}\right)}+\frac{u_{N(\mathrm{SAT})}\left(k^{\prime}+1\right)}{N\left(k^{\prime}+1\right)}\right) .
\end{aligned}
$$

The saturation correction uncertainty then propagates to the sum $S$ defined in Eq. (14), again assuming full correlation between altitude bins:

$u_{S(\mathrm{SAT})}(k)=\sum_{k^{\prime}=k}^{k \mathrm{TOP}-1} \bar{g}\left(k^{\prime}\right) u_{\bar{N}(\mathrm{SAT})}\left(k^{\prime}\right)$.

Finally, the temperature uncertainty owing to saturation correction $u_{T \text { (SAT) }}$ is computed by applying Eq. (2) to the density integration Eq. (13) with the same full correlation assumptions:

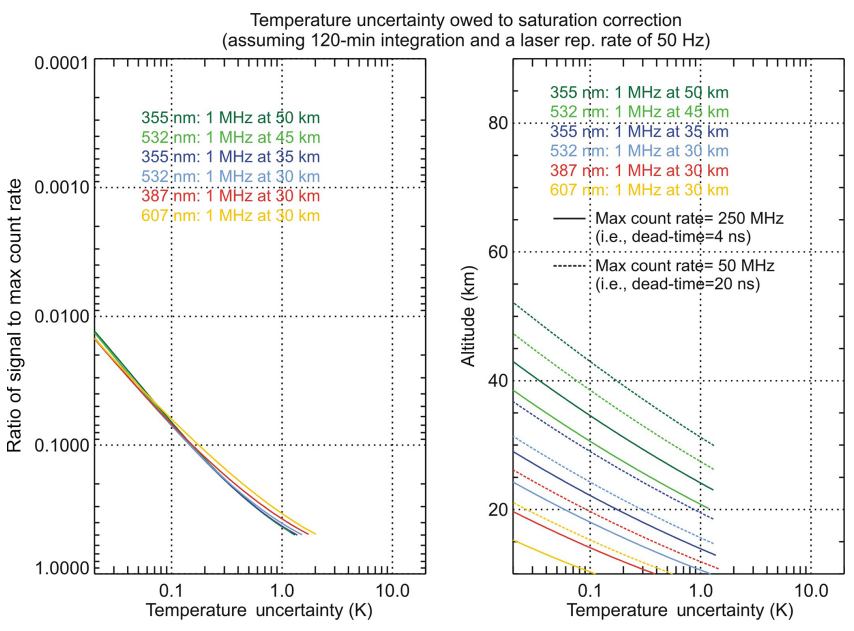

Figure 2. Temperature uncertainty owing to saturation correction as a function of lidar signal magnitude (left) and altitude (right) for a variety of lidar performance configurations (see Fig. 1 caption for details).

$$
\begin{aligned}
& u_{T(\mathrm{SAT})}(k)=\frac{1}{N(k)} \\
& \left|T(k) u_{N(\mathrm{SAT})}(k)-T_{\mathrm{a}}\left(k_{\mathrm{TOP}}\right) u_{N(\mathrm{SAT})}\left(k_{\mathrm{TOP}}\right)-\frac{M_{\mathrm{a}} \delta z}{R_{\mathrm{a}}} u_{S(\mathrm{SAT})}(k)\right| .
\end{aligned}
$$

Figure 2 shows the order of magnitude of this uncertainty component as a function of signal strength (left) and altitude (right) for two saturation correction cases, namely if the dead time is $20 \mathrm{~ns}$ (max. count rate of $50 \mathrm{MHz}$, dashed curves), and if the dead time is $4 \mathrm{~ns}$ ( $\max$ count rate of $250 \mathrm{MHz}$, solid curves). As for detection noise uncertainty, the results are presented in generic form so that the actual order of magnitude of this uncertainty component can be easily estimated for lidar systems of any performance. Here, the same family of curves is obtained when the uncertainty is represented as a function of the ratio of the signal to the maximum counting rate (left plot).

\subsection{Uncertainty owing to background noise extraction}

Background noise is typically subtracted from the total signal by fitting the uppermost part of the lidar signal with a constant, linear, or nonlinear function of altitude. An uncertainty component associated with the noise fitting procedure should be introduced. Here we consider the simple case of a linear fit, knowing that exactly the same approach can be used for other fitting functions. The linear fitting function to be estimated can be written as follows:

$B(k)=b_{0}+b_{1} z(k)$.

For standard fitting methods such as least-squares, the uncertainty $u_{b i}$ and correlation coefficients $r_{b i, b j}$ of the fitting coefficients $b_{i}$ can be calculated analytically (type A estimation) (Press et al., 1986). Using the subscript (BKG) for 
background noise, the background noise correction uncertainty can then be introduced by applying Eq. (2) to the signal transformation Eq. (11):

$u_{P(\mathrm{BKG})}(k)=\sqrt{u_{b 0}^{2}+u_{b 1}^{2} z^{2}(k)+2 z(k) \operatorname{cov}\left(b_{0}, b_{1}\right)}$.

The above expression can be expanded and/or modified based on the actual form of the fitting function, and taking into account the fitting coefficients' covariance matrix returned by the fitting routine. Just like the saturation correction uncertainty, the uncertainty component owing to the background noise extraction can be propagated through the temperature retrieval, assuming full correlation in altitude. Applying Eq. (2) to the signal transformations Eqs. (12)-(15) therefore yields

$u_{N(\mathrm{BKG})}(k)=\frac{N(k)}{P(k)} u_{P(\mathrm{BKG})}(k)$

$u_{\bar{N}(\mathrm{BKG})}\left(k^{\prime}\right)=\frac{\bar{N}\left(k^{\prime}\right)}{2}\left(\frac{u_{N(\mathrm{BKG})}\left(k^{\prime}\right)}{N\left(k^{\prime}\right)}+\frac{u_{N(\mathrm{BKG})}\left(k^{\prime}+1\right)}{N\left(k^{\prime}+1\right)}\right)$

$u_{S(\mathrm{BKG})}(k)=\sum_{k^{\prime}=k}^{k \mathrm{TOP}-1} \bar{g}\left(k^{\prime}\right) u_{\bar{N}(\mathrm{BKG})}\left(k^{\prime}\right)$

$u_{T(\mathrm{BKG})}(k)=\frac{1}{N(k)}$

$\left|T(k) u_{N(\mathrm{BKG})}(k)-T_{\mathrm{a}}\left(k_{\mathrm{TOP}}\right) u_{N(\mathrm{BKG})}\left(k_{\mathrm{TOP}}\right)-\frac{M_{\mathrm{a}} \delta z}{R_{\mathrm{a}}} u_{S(\mathrm{BKG})}(k)\right|$.

The order of magnitude of this uncertainty component depends on the magnitude of the background noise, and if signal-induced noise is present on the slope of this noise with respect to the signal slope. Figure 3 shows several examples of constant background noise of varying magnitude. The temperature uncertainty is represented here as a function of altitude (top-left), distance from the tie-on altitude (topright), signal-to-noise ratio (bottom-left), and statistical uncertainty (bottom-right). The curves show a systematic pattern which consists of a rapid increase in the first 3-4 km below the tie-on altitude as density is integrated downward, followed by a decrease as we get further and further from the tie-on altitude. The $e$-folding rate is $7 \mathrm{~km}$ for the entire family of curves, which reflects the main influence of the $1 / \mathrm{N}$ term in Eq. (36). The temperature uncertainty maximum is larger when the magnitude of the noise is larger (as shown for the 387 and $607 \mathrm{~nm}$ Raman channels on Fig. 3).

\subsection{Uncertainty owing to Rayleigh extinction cross sections}

All lidar-derived relative density uncertainty components owing to the atmospheric extinction are computed by applying Eqs. (2) to (12). The Rayleigh extinction cross sections
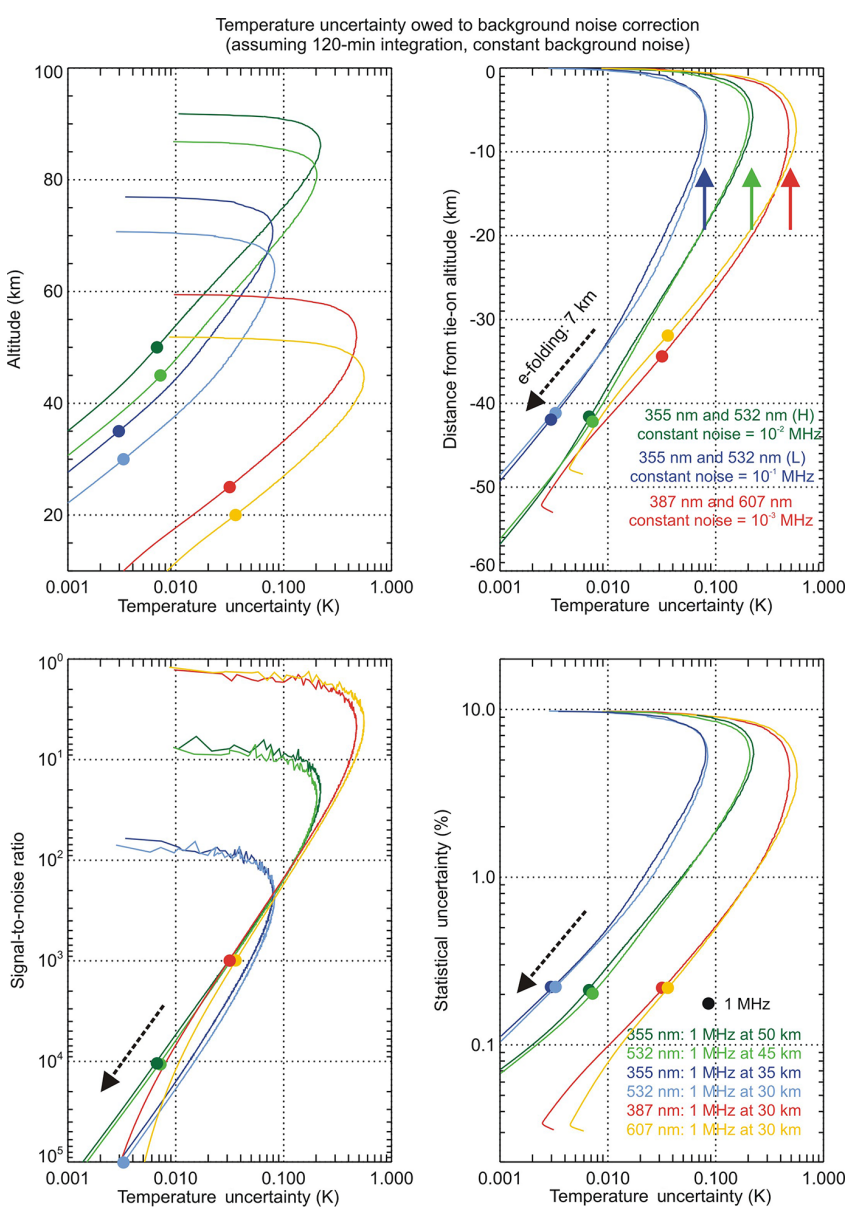

Figure 3. Temperature uncertainty owing to background noise correction as a function of altitude (top-left), distance from tie-on (topright), signal-to-noise ratio (bottom left), and statistical uncertainty (bottom-right), for a variety of signal and noise strengths (see Fig. 1 caption for details).

at the emitted and received wavelengths are among the input quantities. Their values typically originate from theoretical calculations, assuming a given atmospheric composition (see for example Bates, 1984; Eberhard, 2010), and can be assumed constant with altitude (well-mixed atmosphere). A review of the different calculations and the associated uncertainties can be found in Sect. 3.5 and Appendix D of the ISSI team report (Leblanc et al., 2016a). The uncertainty, as reported in the literature, is either owed to random or systematic effects, or both. These two types of uncertainty are not introduced and propagated identically in the lidar temperature measurement model. The subscript suffixes $R^{\prime}$ (for random) and $S^{\prime}$ (for systematic) are used hereafter to make this distinction. 


\subsubsection{Lidar-derived relative density uncertainty for Rayleigh backscatter channels}

For Rayleigh backscatter channels, the received wavelength $\left(\lambda_{2}\right)$ is identical to the emitted wavelength $\left(\lambda_{1}\right)$, and the cross section uncertainty owing to random and systematic effects is introduced and propagated identically throughout the temperature retrieval. Using the subscript $(\sigma M)^{\prime}$ ' for molecular extinction cross section uncertainty component, and the suffixes $R^{\prime}$ and $S^{\prime}$ for random and systematic components respectively, the Rayleigh extinction cross section uncertainty owing to random and systematic effects can be propagated to the lidar-derived relative density $N$ by applying Eqs. (2) to (12):

$u_{N(\sigma M X)}(k)=2 N(k) \delta z \sum_{k^{\prime}=0}^{k} N_{\mathrm{a}}\left(k^{\prime}\right) u_{\sigma M_{-} 1 X}$,

with $X=R, S$.

\subsubsection{Lidar-derived relative density uncertainty for Raman backscatter channels}

For Raman backscatter channels (Strauch et al., 1971), the received and emitted wavelengths are different, and the cross section uncertainty owing to random and systematic effects is introduced and propagated differently. For the uncertainty component owing to random effect, applying Eqs. (2) to (11) yields

$u_{N(\sigma M R)}(k)=N(k) \delta z \sum_{k^{\prime}=0}^{k} N_{\mathrm{a}}\left(k^{\prime}\right) \sqrt{u_{\sigma M_{-} 1 R}^{2}+u_{\sigma M_{-} 2 R}^{2}}$.

For the uncertainty component owing to systematic effects, applying Eqs. (2) to (12) yields

$u_{N(\sigma M S)}(k)=N(k) \delta z \sum_{k^{\prime}=0}^{k} N_{\mathrm{a}}\left(k^{\prime}\right)\left(u_{\sigma M_{-} 1 S}+u_{\sigma M_{-} 2 S}\right)$.

\subsubsection{Propagation to temperature}

For both Rayleigh and Raman backscatter, both random and systematic components of the lidar-derived relative density uncertainty owing to Rayleigh extinction cross sections are propagated to temperature similarly to the saturation and background uncertainty components (e.g., Eqs. 28-30):

$u_{\bar{N}(\sigma M X)}\left(k^{\prime}\right)=\frac{\bar{N}\left(k^{\prime}\right)}{2}\left(\frac{u_{N(\sigma M X)}\left(k^{\prime}\right)}{N\left(k^{\prime}\right)}+\frac{u_{N(\sigma M X)}\left(k^{\prime}+1\right)}{N\left(k^{\prime}+1\right)}\right)$,

with $X=R, S$.

$u_{S(\sigma M X)}(k)=\sum_{k^{\prime}=k}^{k \mathrm{TOP}-1} \bar{g}\left(k^{\prime}\right) u_{\bar{N}(\sigma M X)}\left(k^{\prime}\right)$,

with $X=R, S$.

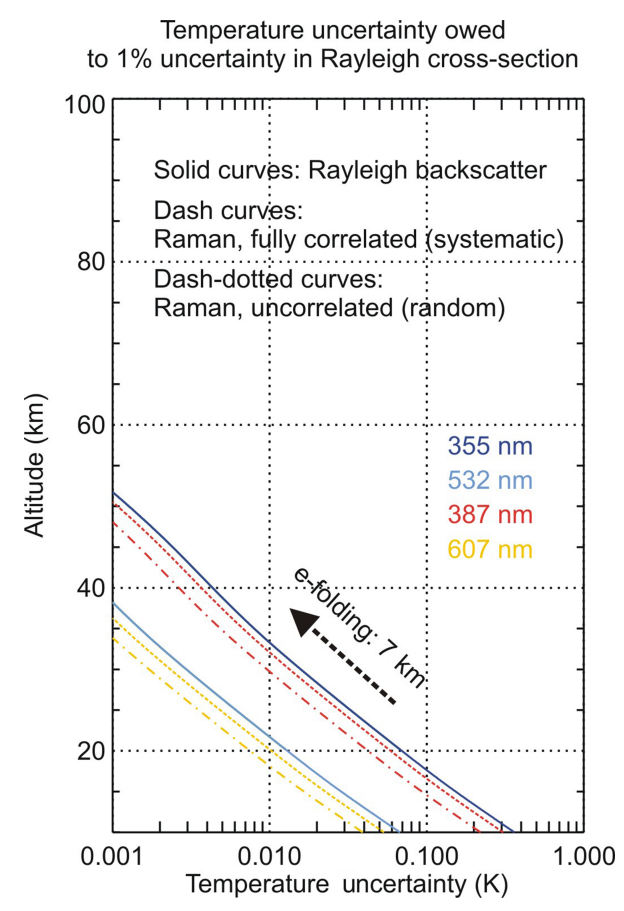

Figure 4. Temperature uncertainty owing to the Rayleigh cross section used in the molecular extinction correction. The results are shown per $1 \%$ in cross section uncertainty.

$$
\begin{aligned}
& u_{T(\sigma M X)}(k)=\frac{1}{N(k)} \\
& \mid T(k) u_{N(\sigma M X)}(k)-T_{\mathrm{a}}\left(k_{\mathrm{TOP}}\right) u_{N(\sigma M X)}\left(k_{\mathrm{TOP}}\right) \\
& -\frac{M_{\mathrm{a}} \delta z}{R_{\mathrm{a}}} u_{S(\sigma M X)}(k) \mid, \text { with } X=R, S .
\end{aligned}
$$

The magnitude of the uncertainty owing to the Rayleigh cross sections is plotted in Fig. 4 for four different wavelengths and for components owing to both systematic and random effects. The results are shown for each $1 \%$ cross section uncertainty; i.e., if the cross section is introduced in the lidar measurement model with a $5 \%$ uncertainty, then the temperature uncertainty will be 5 times larger than shown in Fig. 4. Again for all curves, the $e$-folding rate is $7 \mathrm{~km}$, which reflects the dominant influence of the term $1 / N$ in Eq. (44).

\subsection{Uncertainty owing to air number density}

An ancillary profile of air number density $\left(N_{\mathrm{a}}\right)$ is needed to correct for Rayleigh extinction as formulated in Eq. (12). Air number density is generally not estimated directly, but is rather derived from air temperature and pressure. First we will consider the case of number density being the input quantity, then we will consider the case of temperature and pressure being the input quantities. 


\subsubsection{If air number density is the input quantity}

Here, it is assumed that the air density profile $N_{\mathrm{a}}$ is made of fully correlated values in altitude. If air number density is not derived from air temperature and pressure, its uncertainty $u_{N_{\mathrm{a}}}$ is propagated to the lidar-derived relative density by applying Eqs. (2) to (12) in a straightforward manner:

$u_{N\left(N_{\mathrm{a}}\right)}(k)=N(k) \delta z\left(\sigma_{\mathrm{M} \_1}+\sigma_{\mathrm{M} \_2}\right) \sum_{k^{\prime}=0}^{k} u_{N_{\mathrm{a}}}\left(k^{\prime}\right)$.

This component is then propagated to temperature using the same approach as for saturation and background noise correction uncertainties.

\subsubsection{If air temperature and pressure are the input quantities}

When the ancillary number density is computed from an ancillary temperature $T_{\mathrm{a}}$ and pressure $p_{\mathrm{a}}$ source (e.g., radiosonde measurements or meteorological models), the uncertainties $u_{T_{\mathrm{a}}}$ and $u_{\mathrm{pa}}$ must be introduced and the degree of correlation between temperature and pressure must be estimated.

If temperature and pressure are measured or computed independently, then the complete covariance matrix in the vertical dimension needs to be estimated. This is the most complex case to consider because of the interplay between the lack of correlation between $T_{\mathrm{a}}$ and $p_{\mathrm{a}}$ at any given altitude, and the high correlation between the temperature values at two consecutive altitudes, or between the pressure values at two consecutive altitudes. However, a good approximation consists of considering the propagation linear, i.e., first combining the uncertainties at one fixed level assuming no correlation, and then propagating the combined uncertainty assuming full correlation between two consecutive altitudes. In this case, the lidar-derived relative density uncertainty owing to the ancillary air number density can be written as follows:

$$
\begin{gathered}
u_{N\left(N_{\mathrm{a}}\right)}(k)=N(k) \delta z \sum_{k^{\prime}=0}^{k}\left(\sigma_{\mathrm{M} \_1}+\sigma_{\mathrm{M} \_2}\right) N_{\mathrm{a}}\left(k^{\prime}\right) \\
\sqrt{\frac{u_{\mathrm{pa}}^{2}\left(k^{\prime}\right)}{p_{\mathrm{a}}^{2}\left(k^{\prime}\right)}+\frac{u_{T_{\mathrm{a}}}^{2}\left(k^{\prime}\right)}{T_{\mathrm{a}}^{2}\left(k^{\prime}\right)}} .
\end{gathered}
$$

If temperature and pressure are known to be fully correlated, then the lidar-derived relative density uncertainty owing to the ancillary air number density becomes

$u_{N\left(N_{\mathrm{a}}\right)}(k)=$

$N(k) \delta z \sum_{k^{\prime}=0}^{k}\left(\sigma_{\mathrm{M}_{-} 1}+\sigma_{\mathrm{M}_{-} 2}\right) N_{\mathrm{a}}\left(k^{\prime}\right)\left|\frac{u_{\mathrm{pa}}\left(k^{\prime}\right)}{p_{\mathrm{a}}\left(k^{\prime}\right)}-\frac{u_{T_{\mathrm{a}}}\left(k^{\prime}\right)}{T_{\mathrm{a}}\left(k^{\prime}\right)}\right|$.

\subsubsection{Propagation to temperature}

The lidar-derived number density uncertainty owing to ancillary air number density is propagated to temperature by

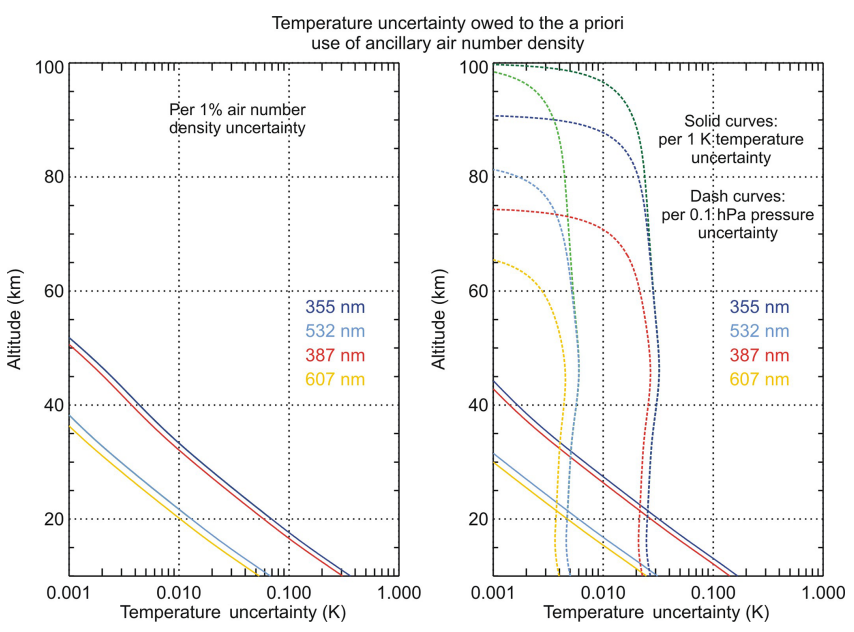

Figure 5. Temperature uncertainty owing to the a priori use of ancillary air number density in the molecular extinction correction. The results are shown per $1 \%$ ancillary number density uncertainty (left plot), and per $1 \mathrm{~K}$ and $0.1 \mathrm{hPa}$ ancillary temperature and pressure uncertainty respectively (right plot).

applying Eq. (2) to Eqs. (13)-(15), assuming full correlation in altitude:

$$
\begin{aligned}
& u_{\bar{N}\left(N_{\mathrm{a}}\right)}\left(k^{\prime}\right)=\frac{\bar{N}\left(k^{\prime}\right)}{2}\left(\frac{u_{N\left(N_{\mathrm{a}}\right)}\left(k^{\prime}\right)}{N\left(k^{\prime}\right)}+\frac{u_{N\left(N_{\mathrm{a}}\right)}\left(k^{\prime}+1\right)}{N\left(k^{\prime}+1\right)}\right) \\
& u_{S\left(N_{\mathrm{a}}\right)}(k)=\sum_{k^{\prime}=k}^{k \mathrm{TOP}-1} \bar{g}\left(k^{\prime}\right) u_{\bar{N}\left(N_{\mathrm{a}}\right)}\left(k^{\prime}\right) \\
& u_{T\left(N_{\mathrm{a}}\right)}(k)=\frac{1}{N(k)} \\
& \left|T(k) u_{N\left(N_{\mathrm{a}}\right)}(k)-T_{\mathrm{a}}\left(k_{\mathrm{TOP}}\right) u_{N\left(N_{\mathrm{a}}\right)}\left(k_{\mathrm{TOP}}\right)-\frac{M_{\mathrm{a}} \delta z}{R_{\mathrm{a}}} u_{S\left(N_{\mathrm{a}}\right)}(k)\right| .
\end{aligned}
$$

Figure 5 shows the magnitude of this uncertainty component, assuming either that the input quantity is the air number density (left plot), or that the input quantities are temperature and pressure (right plot). In the first case, the results are shown for $1 \%$ uncertainty in ancillary air number density. In the second case, the results are plotted for $1 \mathrm{~K}$ ancillary temperature uncertainty (solid curves) and $0.1 \mathrm{hPa}$ ancillary pressure uncertainty (dashed curves). The shape of the dashed curves do not show the normal $7 \mathrm{~km} e$-folding rate because of the emerging very high pressure relative uncertainty associated with a fixed $0.1 \mathrm{hPa}$ value. The $e$-folding rate would be similar to the other curves if the ancillary pressure uncertainty were set to be constant in relative value rather than absolute.

\subsection{Uncertainty owing to the ozone and $\mathrm{NO}_{2}$ absorption cross sections}

Temperature-dependent ozone and $\mathrm{NO}_{2}$ absorption cross section values typically can be found in published works originating from spectroscopy groups around the world 
(e.g., Brion et al., 1998; Daumont et al., 1992; Bogumil et al., 2003; Chehade et al., 2013; Gorshelev et al., 2014; Burkholder and Talukdar, 1994; Burrows et al., 1999; Vandaele et al., 1998). The random component of the cross section uncertainty is normally provided in these works. Occasionally, one or more components owing to systematic effects are also provided. For the ozone absorption cross section, a review and assessment of the available datasets is summarized in Sect. 3.5 and Appendix E of the ISSI team report (Leblanc et al., 2016a). Just like for Rayleigh extinction cross sections, these two types of component are not introduced and propagated identically in the lidar temperature measurement model. The formulation of their propagation is identical to that just presented for Rayleigh extinction cross sections (Eqs. 40-44), except that the air number density is replaced by the interfering gas number density, and the cross section uncertainty is now a function of temperature, i.e., altitude.

For Rayleigh backscatter channels,

$u_{N(\sigma \operatorname{ig} X)}(k)=2 N(k) \delta z \sum_{k^{\prime}=0}^{k} N_{\mathrm{O}_{3}}\left(k^{\prime}\right) u_{\sigma \mathrm{ig} \_1 X}\left(k^{\prime}\right)$,

with ig $=\mathrm{O}_{3}, \mathrm{NO}_{2}$ and $X=R, S$.

For Raman backscatter channels,

$u_{N(\sigma \operatorname{ig} R)}(k)=N(k) \delta z$

$\sqrt{\sum_{k^{\prime}=0}^{k} N_{\text {ig }}^{2}\left(k^{\prime}\right)\left(u_{\sigma \text { ig_1 } 2}^{2}\left(k^{\prime}\right)+u_{\sigma \text { ig_2 } 2 R}^{2}\left(k^{\prime}\right)\right)}$,

with ig $=\mathrm{O}_{3}, \mathrm{NO}_{2}$.

$u_{N(\sigma \operatorname{ig} S)}(k)=$

$N(k) \delta z \sum_{k^{\prime}=0}^{k} N_{\mathrm{a}}\left(k^{\prime}\right)\left(u_{\sigma \text { ig_1S }}\left(k^{\prime}\right)+u_{\sigma \text { ig__2S }}\left(k^{\prime}\right)\right)$,

with ig $=\mathrm{O}_{3}, \mathrm{NO}_{2}$.

Their propagation to temperature can then be written as follows:

$u_{\bar{N}(\sigma \operatorname{ig} X)}\left(k^{\prime}\right)=$

$\frac{\bar{N}\left(k^{\prime}\right)}{2}\left(\frac{u_{N(\sigma \operatorname{ig} X)}\left(k^{\prime}\right)}{N\left(k^{\prime}\right)}+\frac{u_{N(\sigma \operatorname{ig} X)}\left(k^{\prime}+1\right)}{N\left(k^{\prime}+1\right)}\right)$,

with ig $=\mathrm{O}_{3}, \mathrm{NO}_{2}$ and $X=R, S$.

$u_{S(\sigma \operatorname{ig} X)}(k)=\sum_{k^{\prime}=k}^{k \mathrm{TOP}-1} \bar{g}\left(k^{\prime}\right) u_{\bar{N}(\sigma \operatorname{ig} X)}\left(k^{\prime}\right)$,

with ig $=\mathrm{O}_{3}, \mathrm{NO}_{2}$ and $X=R, S$.

$u_{T(\sigma \operatorname{ig} X)}(k)=\frac{1}{N(k)}$

$\mid T(k) u_{N(\sigma \operatorname{ig} X)}(k)-T_{\mathrm{a}}\left(k_{\mathrm{TOP}}\right) u_{N(\sigma \operatorname{ig} X)}\left(k_{\mathrm{TOP}}\right)$

$-\frac{M_{\mathrm{a}} \delta z}{R_{\mathrm{a}}} u_{S(\sigma \mathrm{ig} X)}(k) \mid \mathrm{ig}=\mathrm{O}_{3}, \mathrm{NO}_{2} ; X=R, S$.
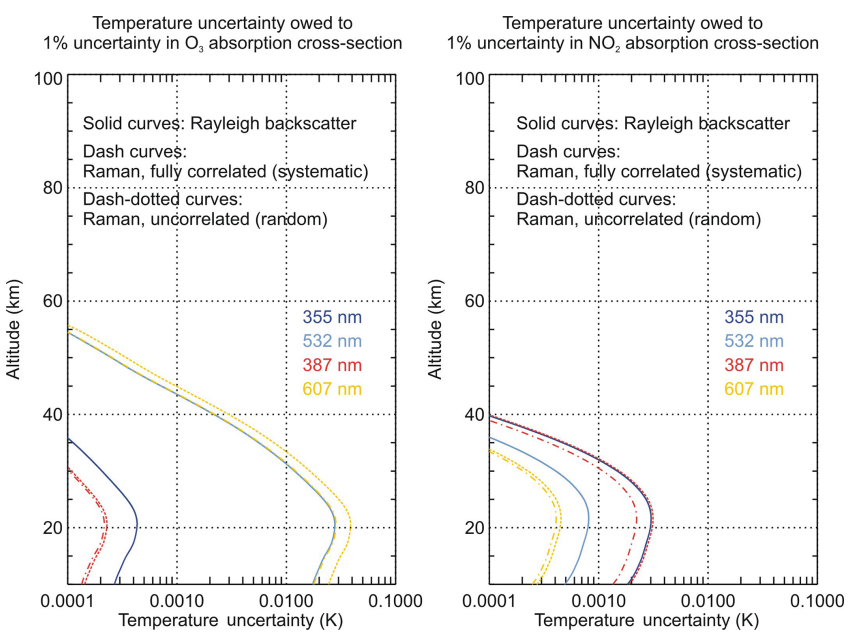

Figure 6. Temperature uncertainty owing to the cross sections used for the ozone and $\mathrm{NO}_{2}$ absorption correction. The results are shown per $1 \%$ in cross section uncertainty (left side: ozone, right side: $\mathrm{NO}_{2}$ ), and for components owing to both systematic and random effects.

The magnitude of this uncertainty component owing to both systematic and random effects is shown in Fig. 6 for both Rayleigh and Raman backscatter cases and different wavelengths. The contribution of ozone absorption (left plot) is larger in the visible (532 and $607 \mathrm{~nm}$ which are both in the Chappuis band) than in the ultraviolet spectrum (355 and $387 \mathrm{~nm}$ ). Conversely, the contribution of $\mathrm{NO}_{2}$ absorption (right plot) is larger in the ultraviolet than in the visible spectrum.

\subsection{Uncertainty owing to ancillary ozone and $\mathrm{NO}_{2}$ number density profiles}

The ozone and $\mathrm{NO}_{2}$ absorption terms in Eq. (12) comprise the sum of ancillary ozone and $\mathrm{NO}_{2}$ number densities taken at all altitudes from the ground to the altitude considered $z(k)$. Depending on the data source, these ancillary profiles may be mixing ratio or number density (Ahmad et al., 2007; Bauer et al., 2012; Bracher et al., 2005; Brohede et al., 2007). Assuming that all values within the same ancillary profile are fully correlated, uncertainty components owing to the ancillary ozone and $\mathrm{NO}_{2}$ profiles can be propagated to temperature similarly to the uncertainty component owing to air number density (i.e., Eq. 45 and Eqs. 48-50):

$u_{N(\mathrm{~N} i g)}(k)=N(k) \sum_{k^{\prime}=0}^{k}\left(\sigma_{\text {ig_1 }}\left(k^{\prime}\right)+\sigma_{\text {ig_2 }}\left(k^{\prime}\right)\right) u_{N i g}\left(k^{\prime}\right)$,

with ig $=\mathrm{O}_{3}, \mathrm{NO}_{2}$,

$u_{\bar{N}(\mathrm{~N} i g)}\left(k^{\prime}\right)=\frac{\bar{N}\left(k^{\prime}\right)}{2}\left(\frac{u_{N(\mathrm{~N} i g)}\left(k^{\prime}\right)}{N\left(k^{\prime}\right)}+\frac{u_{N(\mathrm{~N} i g)}\left(k^{\prime}+1\right)}{N\left(k^{\prime}+1\right)}\right)$ 

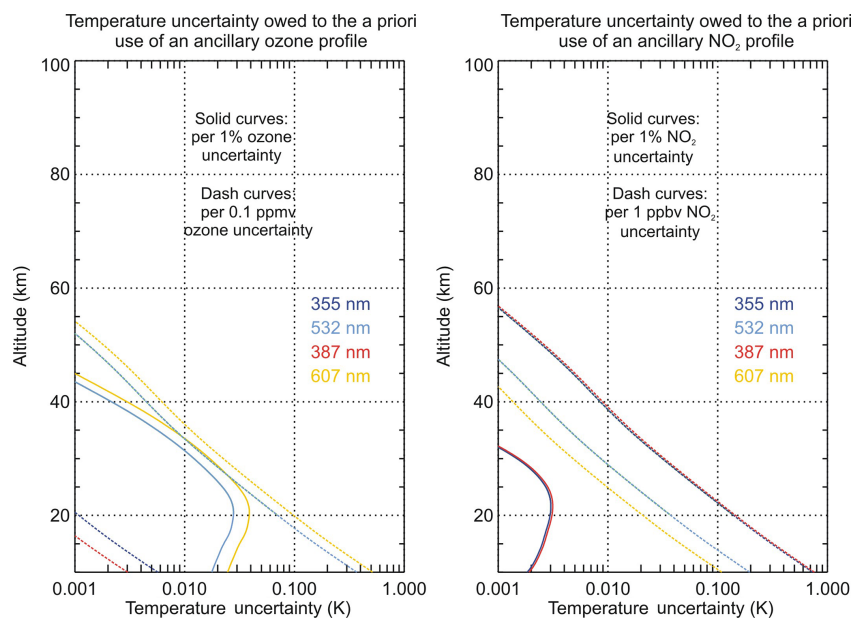

Figure 7. Temperature uncertainty owing to the a priori use of ancillary ozone number density (left) and $\mathrm{NO}_{2}$ number density (right) for the absorption correction. The results are shown per $1 \%$ uncertainty (solid curves), and for 1 ppmv ozone uncertainty (dashed curves, left) and 1 ppbv $\mathrm{NO}_{2}$ uncertainty (dashed curves, right).

$u_{S(\mathrm{~N} i g)}(k)=\sum_{k^{\prime}=k}^{k \mathrm{TOP}-1} \bar{g}\left(k^{\prime}\right) u_{\bar{N}(\mathrm{~N} i g)}\left(k^{\prime}\right)$

$u_{T(\mathrm{~N} i g)}(k)=$

$\frac{1}{N(k)}$

$\left|T(k) u_{N(\mathrm{~N} i g)}(k)-T_{\mathrm{a}}\left(k_{\mathrm{TOP}}\right) u_{N(\mathrm{~N} i g)}\left(k_{\mathrm{TOP}}\right)-\frac{M_{\mathrm{a}} \delta z}{R_{\mathrm{a}}} u_{S(\mathrm{~N} i g)}(k)\right|$.

Figure 7 shows the magnitude of this uncertainty component for both ozone (left) and $\mathrm{NO}_{2}$ (right), for both Rayleigh and Raman backscatter cases, and for different wavelength bands. The results are shown per $1 \%$ ancillary ozone and $\mathrm{NO}_{2}$ uncertainty (solid curves), and per $1 \mathrm{ppmv}$ ancillary ozone (respectively 1 ppbv ancillary $\mathrm{NO}_{2}$ ) uncertainty (dashed curves). Similarly to the temperature uncertainty owing to the absorption cross sections, the contribution of ozone is larger in the visible than in the ultraviolet, and the contribution of $\mathrm{NO}_{2}$ is larger in the ultraviolet than in the visible.

\subsection{Uncertainty owing to the temperature tie-on at the top of the profile}

Equation (12) shows that an ancillary temperature value $T_{\mathrm{a}}$ at altitude $z\left(k_{\mathrm{TOP}}\right)$ is needed to initialize the profile at the top. Using the subscript (TIE) for tie-on, the ancillary temperature uncertainty $u_{T_{\mathrm{a}}}\left(k_{\mathrm{TOP}}\right)$ is propagated to the retrieved temperature profile by applying Eqs. (2) to (13):

$u_{T(\mathrm{TIE})}(k)=\frac{N\left(k_{\mathrm{TOP}}\right)}{N(k)} u_{T_{\mathrm{a}}}\left(k_{\mathrm{TOP}}\right)$.

The magnitude of this uncertainty component is plotted in Fig. 8 for a $1 \mathrm{~K}$ tie-on ancillary temperature uncertainty and

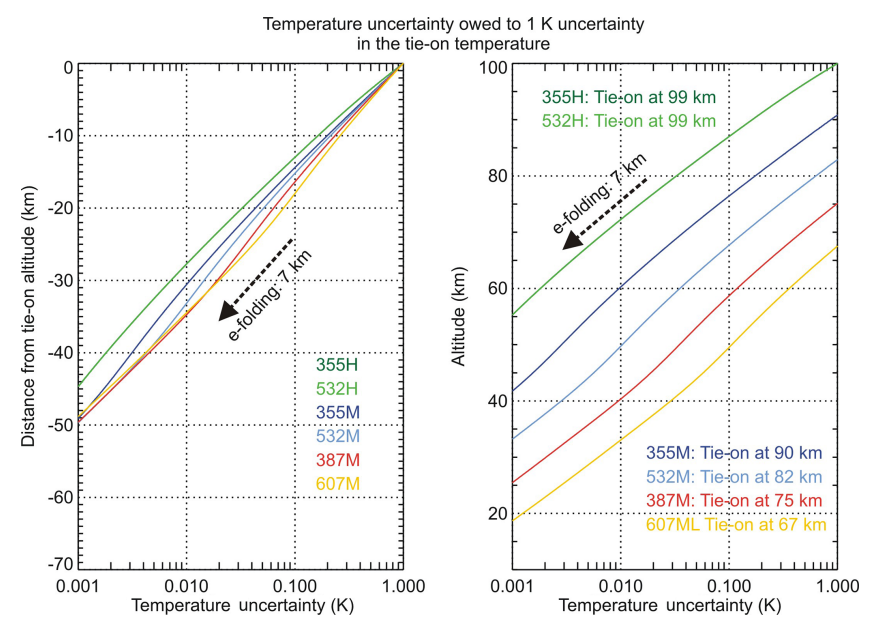

Figure 8. Temperature uncertainty owing to a priori use of ancillary temperature to tie-on at the start of the density integration process. The results are shown per $1 \mathrm{~K}$ ancillary temperature uncertainty.

for several lidar performance cases. As expected, we obtain a family of curves with an approximate $e$-folding rate of $7 \mathrm{~km}$ due to the term $1 / N$ in Eq. (47).

\subsection{Uncertainty owing to the acceleration of gravity}

The acceleration of gravity is an input quantity introduced in Eq. (14). The constants $g_{0}, g_{1}$, and $g_{2}$ relate to the Earth's geometry and to the geodetic latitude of the lidar site. If a value of the local ellipsoid height at the lidar site $h(0)$ is not known, we can approximate it to the site's altitude above mean sea level $z(0)$. For all altitude-dependent and latitude-dependent formulations of the acceleration of gravity, the difference between $h(0)$ and $z(0)$ is by far the largest source of error in the computation of the acceleration of gravity. We therefore can define a new uncertainty component $u_{\mathrm{h}}$ associated with the approximation of $h$. The values of $h$ at neighboring altitudes are fully correlated, and their standard uncertainty can be deduced directly from Eq. (17):

$u_{\bar{h}}\left(k^{\prime}\right)=\frac{1}{2}\left(u_{\mathrm{h}}\left(k^{\prime}\right)+u_{\mathrm{h}}\left(k^{\prime}+1\right)\right)$.

The height uncertainty is then propagated to temperature by applying Eq. (2) to Eqs. (13)-(16):

$u_{T(g)}(k)=$

$\frac{1}{N(k)} \frac{M_{\mathrm{a}} \delta z}{R_{\mathrm{a}}} g_{0} \sum_{k^{\prime}=k}^{k \mathrm{TOP}-1} \bar{N}\left(k^{\prime}\right)\left(g_{1}+2 g_{2} \bar{h}\left(k^{\prime}\right)\right) u_{\bar{h}}\left(k^{\prime}\right)$.

Figure 9 shows the magnitude of this uncertainty component per $0.1 \%$ uncertainty in the acceleration of gravity. The results are shown in Kelvin and as a function of altitude (right plot), but also in percent and as a function of the distance from the tie-on altitude (left plot) to illustrate the direct relationship between gravity relative uncertainty and temperature relative uncertainty. 

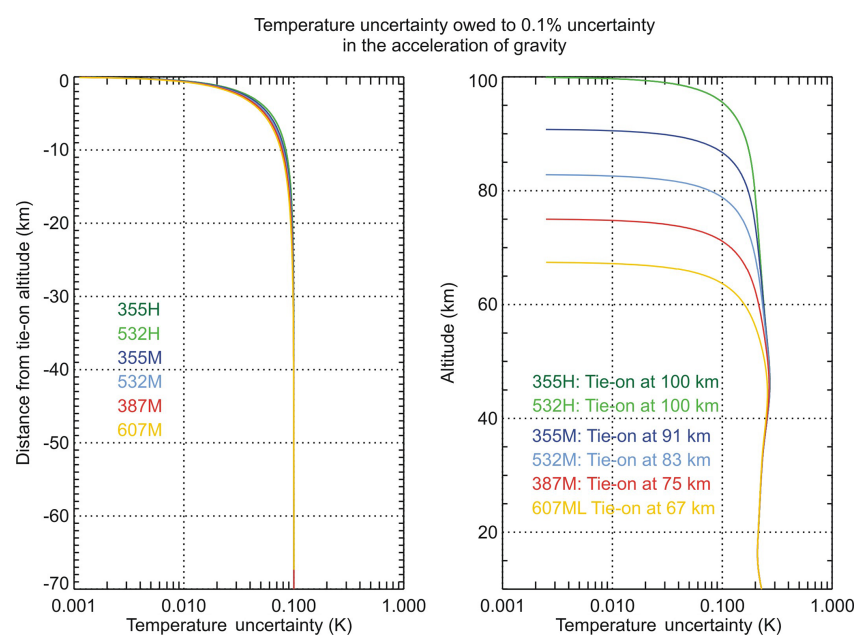

Figure 9. Temperature uncertainty owing to $0.1 \%$ uncertainty in the acceleration of gravity. Left: relative uncertainty (\%) as a function of the distance from the tie-on altitude. Right: absolute uncertainty $(\mathrm{K})$ as a function of altitude.

\subsection{Uncertainty owing to the molecular mass of air}

The molecular mass of dry air $M_{\mathrm{a}}$ is introduced in Eq. (13). Its uncertainty $u_{M_{\mathrm{a}}}$ can be propagated to temperature using

$u_{T\left(M_{\mathrm{a}}\right)}(k)=\frac{\delta z}{R_{\mathrm{a}}} \frac{S(k)}{N(k)} u_{M_{\mathrm{a}}}$.

This component remains negligible below $90 \mathrm{~km}$, and has a variation with altitude exactly similar to that shown for the acceleration of gravity. Figure 9 can therefore be used for the molecular mass of air without any change to it.

\subsection{Propagation of uncertainty when vertically filtering (smoothing) the lidar signal or temperature profile}

The smoothing procedure was introduced as an optional step in the measurement model. If present, it can be applied either to the lidar signal or to the retrieved temperature profile (see Eqs. 18-19).

\subsubsection{Smoothing the lidar signal before the temperature profile is computed}

From Eq. (17) and using the same notation, the uncertainty component owing to detection noise is propagated to the smoothed signal profile, assuming no correlation between the neighboring points:

$u_{s m(\mathrm{DET})}(k)=s_{\mathrm{m}}(k) \sqrt{\sum_{p=-n}^{n} c_{\mathrm{p}}^{2}(k) \frac{u_{s(\mathrm{DET})}^{2}(k+p)}{s^{2}(k+p)}}$.

For all other uncertainty components except temperature tieon, acceleration of gravity, and the molecular mass of air, full correlation is assumed between the neighboring points, and the uncertainty in the smoothed signal can be written as follows:

$u_{s m(X)}(k)=s_{\mathrm{m}}(k) \sum_{p=-n}^{n} c_{\mathrm{p}}(k) \frac{u_{s(X)}(k+p)}{s(k+p)}$,

with $X=\mathrm{SAT}$, BKG, $\sigma M R, \sigma M S, N_{\mathrm{a}}, \sigma \operatorname{ig} R, \sigma \operatorname{ig} S$, and $N$ ig.

The uncertainty components owing to temperature tie-on, acceleration of gravity, and the molecular mass of air are not included in the above expression because they are introduced later in the data processing. In this case, Eqs. (61)(64) apply directly to the temperature profile retrieved from the smoothed lidar-derived number density.

\subsubsection{Smoothing the retrieved temperature profile}

From Eq. (19) and using the same notation, the temperature uncertainty components owing to detection noise are propagated to the smoothed temperature profile, assuming no correlation between neighboring points:

$u_{T m(\mathrm{DET})}(k)=\sqrt{\sum_{p=-n}^{n} c_{\mathrm{p}}^{2}(k) u_{T(\mathrm{DET})}^{2}(k+p)}$.

For all other uncertainty components, full correlation is assumed between the two channels:

$u_{T m(X)}(k)=\sum_{p=-n}^{n} c_{\mathrm{p}}(k) u_{T(X)}(k+p)$,

with $X=\mathrm{SAT}$, BKG, $\sigma M R, \sigma M S, N_{\mathrm{a}}, \sigma \operatorname{ig} R, \sigma \operatorname{ig} S, N \operatorname{ig}, g$, $T$ TOP, and $M_{\mathrm{a}}$.

\subsection{Propagation of uncertainty when merging multiple channels together}

The merging procedure was again introduced as an optional step in the measurement model. If present, it can be applied either to the lidar signals or temperature profiles.

\subsubsection{Merging lidar signals before the temperature profile is computed}

From Eq. (20) and using the same notation, the uncertainty components of the low and high channels owing to detection noise are propagated to the merged signal profile, assuming no correlation between the two channels:

$u_{s M(S \mathrm{DET})}(k)=s_{\mathrm{M}}(k)$

$\sqrt{\left(w(k) \frac{u_{s m(\mathrm{DET})}\left(k, i_{\mathrm{L}}\right)}{s_{\mathrm{m}}\left(k, i_{\mathrm{L}}\right)}\right)^{2}+\left((1-w(k)) \frac{u_{s m(\mathrm{DET})}\left(k, i_{\mathrm{H}}\right)}{s_{\mathrm{m}}\left(k, i_{\mathrm{H}}\right)}\right)^{2}}$

$k_{1} \leq k \leq k_{2}$ and $0 \leq w(k) \leq 1$.

If the signal to be merged is the lidar-derived relative density $(s=N)$, all uncertainty components owing to atmo- 
spheric extinction propagate to the merge density using

$u_{s M(X)}(k)=s_{\mathrm{M}}(k)$

$\left(w(k) \frac{u_{s m(X)}\left(k, i_{\mathrm{L}}\right)}{s_{\mathrm{m}}\left(k, i_{\mathrm{L}}\right)}+(1-w(k)) \frac{u_{s m(X)}\left(k, i_{\mathrm{H}}\right)}{s_{\mathrm{m}}\left(k, i_{\mathrm{H}}\right)}\right)$

$k_{1} \leq k \leq k_{2}$ and $0 \leq w(k) \leq 1$,

with $X=\sigma M R, \sigma M S, N_{\mathrm{a}}, \sigma \operatorname{ig} R, \sigma \operatorname{ig} S$, and $N \operatorname{ig}$.

For the uncertainty components of instrumental origin (namely, the saturation correction and background noise extraction), the degree of correlation between the channels hardware needs to be estimated before we can use a specific formulation for the propagation of the uncertainty components of instrumental origin. If the two channels use different hardware, they can be assumed to be independent, and the merged signal uncertainties owing to saturation correction and background noise extraction can be written as follows:

$u_{s M(S X)}(k)=s_{\mathrm{M}}(k)$

$\sqrt{\left(w(k) \frac{u_{s m(X)}\left(k, i_{\mathrm{L}}\right)}{s_{\mathrm{m}}\left(k, i_{\mathrm{L}}\right)}\right)^{2}+\left((1-w(k)) \frac{u_{s m(X)}\left(k, i_{\mathrm{H}}\right)}{s_{\mathrm{m}}\left(k, i_{\mathrm{H}}\right)}\right)^{2}}$

$k_{1} \leq k \leq k_{2}$ and $0 \leq w(k) \leq 1$,

with $X=$ SAT, BKG.

If the two channels share the same hardware and if the saturation and background noise corrections have been applied consistently for both channels within the same data processing algorithm, the associated uncertainty components can be propagated to the combined profile, assuming full correlation:

$u_{s M(X)}(k)=s_{\mathrm{M}}(k)$

$\left(w(k) \frac{u_{s m(X)}\left(k, i_{\mathrm{L}}\right)}{s_{\mathrm{m}}\left(k, i_{\mathrm{L}}\right)}+(1-w(k)) \frac{u_{s m(X)}\left(k, i_{\mathrm{H}}\right)}{s_{\mathrm{m}}\left(k, i_{\mathrm{H}}\right)}\right)$

$k_{1} \leq k \leq k_{2}$ and $0 \leq w(k) \leq 1$,

with $X=$ SAT, BKG.

The uncertainty components owing to temperature tie-on, acceleration of gravity, and the molecular mass of air are not included in the above expressions because they are introduced later in the data processing. In this case, Eqs. (47)(50) apply directly to the temperature profile retrieved from the merged lidar-derived number density.

\subsubsection{Merging the temperature profiles retrieved for individual channels}

From Eq. (21) and using the same notation, the temperature uncertainty components of the low and high channels owing to detection noise are propagated to the merged temperature profile, assuming no correlation between the two channels:

$u_{T M(\mathrm{DET})}(k)=$

$\sqrt{\left(w(k) u_{T m(\mathrm{DET})}\left(k, i_{\mathrm{L}}\right)\right)^{2}+\left((1-w(k)) u_{T m(\mathrm{DET})}\left(k, i_{\mathrm{H}}\right)\right)^{2}}$

$k_{1} \leq k \leq k_{2}$ and $0 \leq w(k) \leq 1$.

For all uncertainty components that are not of instrumental origin, full correlation is assumed between the two channels:

$u_{T M(X)}(k)=w(k) u_{T m(X)}\left(k, i_{\mathrm{L}}\right)+(1-w(k)) u_{T m(X)}\left(k, i_{\mathrm{H}}\right)$

$k_{1} \leq k \leq k_{2}$ and $0 \leq w(k) \leq 1$,

with $X=\sigma M R, \sigma M S, N_{\mathrm{a}}, \sigma \operatorname{ig} R, \sigma \operatorname{ig} S, N \operatorname{ig}, g, T \mathrm{TOP}$, and $M_{\mathrm{a}}$.

Just like in the case of merging the signals, for all uncertainty components of instrumental origin (namely, the saturation correction and background noise extraction), the degree of correlation between the channels' hardware needs to be estimated. If the two channels use different hardware, they can be assumed to be independent, and the temperature uncertainties owing to saturation correction and background noise extraction can be written as follows:

$u_{T M(X)}(k)=$

$\sqrt{\left(w(k) u_{T m(X)}\left(k, i_{\mathrm{L}}\right)\right)^{2}+\left((1-w(k)) u_{T m(X)}\left(k, i_{\mathrm{H}}\right)\right)^{2}}$

$k_{1} \leq k \leq k_{2}$ and $0 \leq w(k) \leq 1$,

with $X=$ SAT, BKG.

If the two channels share the same hardware and if the saturation and background noise corrections have been applied consistently for both channels within the same data processing algorithm, the associated uncertainty components can be propagated to the combined profile, assuming full correlation:

$u_{T M(X)}(k)=w(k) u_{T m(X)}\left(k, i_{\mathrm{L}}\right)+(1-w(k)) u_{T m(X)}\left(k, i_{\mathrm{H}}\right)$

$k_{1} \leq k \leq k_{2}$ and $0 \leq w(k) \leq 1$,

with $X=$ SAT, BKG.

\subsection{Temperature combined standard uncertainty}

Now that all the independent uncertainty components considered in our lidar temperature measurement model have been reviewed and propagated, we can combine them into a unique temperature combined standard uncertainty:

$$
\begin{aligned}
& u_{T(\mathrm{DET})}^{2}(k)+u_{T(\mathrm{SAT})}^{2}(k)+u_{T(\mathrm{BKG})}^{2}(k) \\
& +u_{T(T \mathrm{TOP})}^{2}(k)+u_{T(\sigma M R)}^{2}(k) \\
& +u_{T(\sigma M R S)}^{2}(k)+u_{T\left(\mathrm{~N}_{\mathrm{a}}\right)}^{2}(k)+u_{T(g)}^{2}(k) \\
& +u_{T\left(M_{\mathrm{a}}\right)}^{2}(k)+u_{T\left(\sigma \mathrm{O}_{3} R\right)}^{2}(k)+u_{T\left(\sigma \mathrm{O}_{3} S\right)}^{2}(k) \\
& +u_{T\left(\mathrm{NO}_{3}\right)}^{2}(k)+u_{T\left(\sigma \mathrm{NO}_{2} R\right)}^{2}(k) \\
& +u_{T\left(\sigma \mathrm{NO}_{2} S\right)}^{2}(k)+u_{T\left(N_{\mathrm{NO}}\right)}^{2}(k) .
\end{aligned}
$$


Table 2. Input quantities and their uncertainty used to compute the temperature uncertainty budget presented in Fig. 10.

\begin{tabular}{|c|c|c|c|c|c|c|}
\hline $\begin{array}{l}\text { Input } \\
\text { quantity }\end{array}$ & $\begin{array}{l}\text { Dataset } \\
\text { name }\end{array}$ & $\begin{array}{l}\text { Domain of } \\
\text { validity }\end{array}$ & $\begin{array}{l}\text { Uncertainty } \\
\text { estimate } \\
\text { (random) }\end{array}$ & Reference & $\begin{array}{l}\text { Uncert. } \\
\text { name }\end{array}$ & $\begin{array}{l}\text { Uncert. } \\
\text { used } \\
\text { here }\end{array}$ \\
\hline$\sigma_{\mathrm{M}}$ & Eberhard & / & $2 \%$ & Eberhard (2010) & $u_{\sigma M}$ & $2 \%$ \\
\hline \multirow[t]{3}{*}{$T_{\mathrm{a}}$} & MSISE-90 & $>47 \mathrm{~km}$ & $20 \mathrm{~K}$ & Hedin (1991) & \multirow{3}{*}{$u_{T_{\mathrm{a}}}$} & $20 \mathrm{~K}$ \\
\hline & NCEP-NDSC & $30-47 \mathrm{~km}$ & $1-5 \mathrm{~K}$ & Finger et al. (1993) & & $5 \mathrm{~K}$ \\
\hline & Radiosonde & $<30 \mathrm{~km}$ & $0.2-0.5 \mathrm{~K}$ & Hurst et al. (2011) & & $0.5 \mathrm{~K}$ \\
\hline \multirow[t]{3}{*}{$p_{\mathrm{a}}$} & MSISE-90 & $>47 \mathrm{~km}$ & $5 \%$ & Hedin (1991) & \multirow[t]{3}{*}{$u_{\mathrm{pa}}$} & $5 \%$ \\
\hline & NCEP-NDSC & $30-50 \mathrm{~km}$ & $5 \%$ & Finger et al. (1993) & & $5 \%$ \\
\hline & Radiosonde & $<30 \mathrm{~km}$ & $0.3 \mathrm{hPa}$ & Hurst et al. (2011) & & $0.1 \mathrm{hPa}$ \\
\hline$\sigma_{\mathrm{O}_{3}}$ & DMB & $350-830 \mathrm{~nm}$ & $5 \%$ & Brion et al. (1998) & $u_{\sigma \mathrm{O}_{3}}$ & $5 \%$ \\
\hline$N_{\mathrm{O}_{3}}$ & WACCM & $30-100 \mathrm{~km}$ & $10 \%$ & Garcia et al. (2007) & $U_{\mathrm{NO}_{3}}$ & $10 \%$ \\
\hline$\sigma_{\mathrm{NO}_{2}}$ & Bogumil & $200-800 \mathrm{~nm}$ & $3.5 \%$ & Bogumil et al. (2003) & $u_{\sigma \mathrm{NO}_{2}}$ & $5 \%$ \\
\hline$N_{\mathrm{NO}_{2}}$ & WACCM & $10-120 \mathrm{~km}$ & $10 \%$ & Garcia et al. (2007) & $U_{\mathrm{NNO}_{2}}$ & $10 \%$ \\
\hline \multirow{2}{*}{$T_{\mathrm{a}}\left(k_{\mathrm{TOP}}\right)$} & MSISE-90 & $>47 \mathrm{~km}$ & $20 \mathrm{~K}$ & Hedin (1991) & \multirow{2}{*}{$u_{T T O P}$} & $20 \mathrm{~K}$ \\
\hline & NCEP-NDSC & $<47 \mathrm{~km}$ & $5 \mathrm{~K}$ & Finger et al. (1993) & & $5 \mathrm{~K}$ \\
\hline$g$ & WGS-84 & $10-120 \mathrm{~km}$ & $0.002 \%$ & NIMA, 2000 & $u_{g}$ & $0.002 \%$ \\
\hline$M_{\mathrm{a}}$ & CPIM-2007 & $10-120 \mathrm{~km}$ & $0.02 \%$ & CPIM-2007 & $u_{M_{\mathrm{a}}}$ & $0.02 \%$ \\
\hline
\end{tabular}

At the tie-on altitude $z\left(k_{\mathrm{TOP}}\right)$, all uncertainty components should be set to zero except uncertainty owing to the ancillary temperature $u_{T(T T O P)}$. Additionally, when using multiple channels, the temperature combined standard uncertainty should not be computed for individual intensity channels and then merged into a single profile. Instead, the individual uncertainty components should first be propagated to the merged temperature profile and then added in quadrature to obtain the combined standard uncertainty.

If combining multiple profiles measured by the same instrument, for example to compute a climatology, uncertainty components owing to systematic effects in altitude and/or time must remain separated from components owing to random effects. Uncertainty owing to detection noise is always added in quadrature, but for other components, knowledge of the covariance matrix in the time and/or altitude dimension(s) is required (type A or type B estimation). It is therefore strongly recommended that each individual component is always kept, and Eq. (71) should be used only as a "final product".

The NDACC lidar working group has recently adopted a revised format for archiving the lidar profiles in Hierarchical Data Format (HDF) at the NDACC Data Handling Facility. The agreed revised data format/content includes the total combined uncertainty (left side of Eq. (71)), but also the random uncertainty component $\left(u_{T(\mathrm{DET})}\right.$ in Eq. $\left.(71)\right)$, as well the sum (in quadrature) of all systematic components, which is simply obtained by subtracting (in quadrature) the only random component from the total combined uncertainty in Eq. (71).

\section{Example of actual temperature uncertainty budget}

The uncertainty components discussed in the previous section were quantitatively reviewed, for most cases, in parametric form, so that the order of magnitude of each component could be estimated for a wide range of instrument performance. Here we provide an actual example using existing measurements from the Jet Propulsion Laboratory (JPL) stratospheric ozone DIAL at the NDACC site of Mauna Loa Observatory, Hawai'i (MLO). In this example, the input quantities' uncertainty estimates are taken from the JPL in-house data processing software used to process the routine JPL lidar data archived at NDACC. A list of those input quantities and their uncertainty is compiled in Table 2.

The full temperature uncertainty budget is shown in Fig. 10 for a $2 \mathrm{~h}$ measurement obtained on 13 March 2009. The results are presented for a typical variable vertical filtering scheme that accommodates the signal magnitude of the different channels yielding a vertical resolution comprised between $0.3 \mathrm{~km}$ (lower stratosphere) and $5 \mathrm{~km}$ (upper mesosphere). The JPL lidar at MLO comprises three ranges (Rayleigh high-intensity, Rayleigh low-intensity, and Raman), and the figures show the uncertainty profiles for each of them (top-left, top-right, and bottom-left) as well as for the merged profile (bottom-right). The altitudes of transition from one range to another can be identified by looking at the magnitude of the uncertainty owing to saturation correction or to detection noise, which are signal-dependent (light green and red curves respectively). The transition between the Raman channel and the Rayleigh low-intensity channel is at $31 \mathrm{~km}$, and the transition between the Rayleigh lowintensity channel and Rayleigh high-intensity channel is at $33 \mathrm{~km}$. 

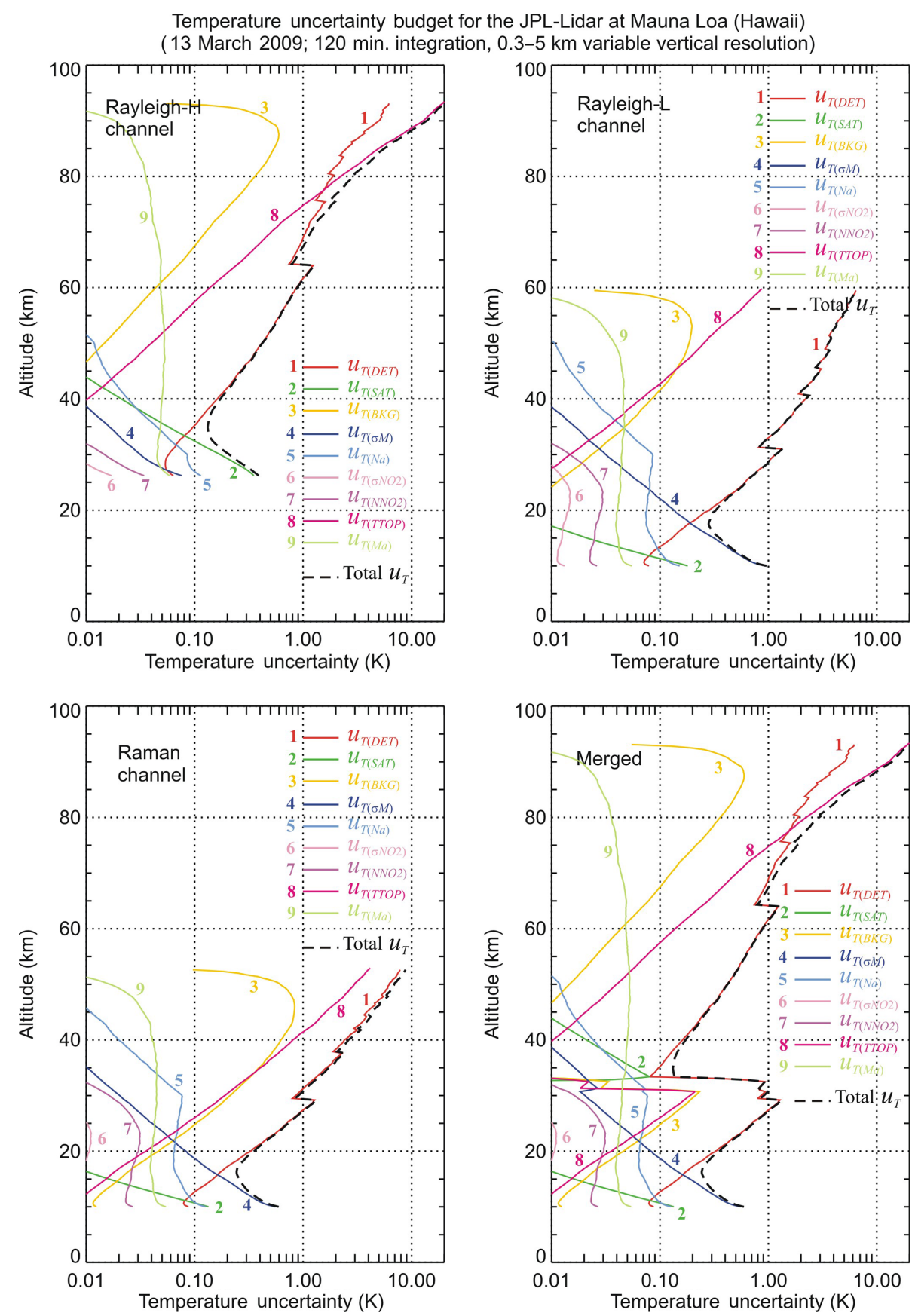

Figure 10. Example of full uncertainty budget for the JPL Mauna Loa Observatory temperature lidar, as computed using the expressions proposed in the present section (data taken during $2 \mathrm{~h}$ on 13 March 2009). Uncertainty components are as follows: 1: detection noise; 2: saturation correction; 3: background correction; 4: Rayleigh scattering cross sections; 5: ancillary air number density; 6: $\mathrm{NO}_{2}$ absorption cross sections; 7: ancillary $\mathrm{NO}_{2}$ number density; 8: temperature tie-on; 9: molecular mass of air.

The combined standard uncertainty of the merged temperature profile (bottom-right plot, black dashed curve) is obtained by first computing the merged profiles of the individual uncertainty components, and then by combining the merged individual components into a single merged total uncertainty profile. The combined uncertainty curves of the in- dividual channels (dash black curves in the top-left, top-right, and bottom left plots) should not be used to compute a combined standard uncertainty for the merged profile.

After optimal combination of all three channels, the temperature standard uncertainty results mainly from four components. At the very bottom $(10-15 \mathrm{~km})$, the dominant source 
Table 3. Example of uncertainty budget for typical NDACC lidars transmitting at 355 and $532 \mathrm{~nm}$ (partial overlap, multiple scattering, and particulate backscatter and extinction are not included, but rough estimates are added in the last row).

\begin{tabular}{|c|c|c|c|c|c|c|}
\hline $\begin{array}{l}\text { Uncertainty } \\
\text { source }\end{array}$ & $\begin{array}{l}\text { Name } \\
\text { in this } \\
\text { manuscript }\end{array}$ & $85 \mathrm{~km}$ & $70 \mathrm{~km}$ & $50 \mathrm{~km}$ & $30 \mathrm{~km}$ & $10 \mathrm{~km}$ \\
\hline $\begin{array}{l}\text { Detection } \\
\text { noise }\end{array}$ & $u_{T(\mathrm{DET})}$ & $\begin{array}{l}\text { High-intensity: } \\
5 \mathrm{~K}\end{array}$ & $\begin{array}{l}\text { High-intensity: } \\
2 \mathrm{~K} \\
\text { Low-intensity: } \\
10 \mathrm{~K}\end{array}$ & $\begin{array}{l}\text { High-intensity: } \\
0.2 \mathrm{~K} \\
\text { Low-intensity: } \\
1 \mathrm{~K}\end{array}$ & $\begin{array}{l}\text { High-intensity: } \\
0.06 \mathrm{~K} \\
\text { Low-intensity: } \\
0.3 \mathrm{~K}\end{array}$ & $\begin{array}{l}\text { Low- } \\
\text { intensity: } \\
0.08 \mathrm{~K}\end{array}$ \\
\hline $\begin{array}{l}\text { Saturation } \\
\text { correction }\end{array}$ & $u_{T(\mathrm{SAT})}$ & I & I & $\begin{array}{l}\text { High-intensity: } \\
0.01 \mathrm{~K}\end{array}$ & $\begin{array}{l}\text { High-intensity: } \\
0.1 \mathrm{~K}\end{array}$ & $\begin{array}{l}\text { Low- } \\
\text { intensity: } \\
0.2 \mathrm{~K}\end{array}$ \\
\hline $\begin{array}{l}\text { Background } \\
\text { correction }\end{array}$ & $u_{T(\mathrm{BKG})}$ & $\begin{array}{l}\text { High-intensity: } \\
0.5 \mathrm{~K}\end{array}$ & $\begin{array}{l}\text { High-intensity: } \\
0.2 \mathrm{~K}\end{array}$ & $\begin{array}{l}\text { Low-intensity: } \\
0.2 \mathrm{~K}\end{array}$ & $\begin{array}{l}\text { Low-intensity: } \\
0.02 \mathrm{~K}\end{array}$ & $\begin{array}{l}\text { Low- } \\
\text { intensity: } \\
0.02 \mathrm{~K}\end{array}$ \\
\hline $\begin{array}{l}\text { Molecular } \\
\text { extinction } \\
\text { cross sections }\end{array}$ & $u_{T(\sigma M)}$ & l & l & l & $\begin{array}{l}355 / 387 \mathrm{~nm}: \\
0.01 \mathrm{~K}\end{array}$ & $\begin{array}{l}355 / 387 \mathrm{~nm}: \\
0.4 \mathrm{~K} \\
532 / 607 \mathrm{~nm}: \\
0.04 \mathrm{~K}\end{array}$ \\
\hline $\begin{array}{l}\text { Ancillary air } \\
\text { density profile }\end{array}$ & $u_{T\left(T_{\mathrm{a}}\right)}$ & l & l & $\begin{array}{l}355 / 387 \mathrm{~nm}: \\
0.01 \mathrm{~K}\end{array}$ & $\begin{array}{l}355 / 387 \mathrm{~nm}: \\
0.05 \mathrm{~K}\end{array}$ & $\begin{array}{l}355 / 387 \mathrm{~nm}: \\
0.05 \mathrm{~K}\end{array}$ \\
\hline $\begin{array}{l}\text { Ozone } \\
\text { absorption } \\
\text { cross sections }\end{array}$ & $u_{T\left(\sigma \mathrm{O}_{3}\right)}$ & I & I & I & $\begin{array}{l}532 / 607 \mathrm{~nm}: \\
0.03 \mathrm{~K}\end{array}$ & $\begin{array}{l}532 / 607 \mathrm{~nm}: \\
0.04 \mathrm{~K}\end{array}$ \\
\hline $\begin{array}{l}\text { Ancillary } \\
\text { ozone profile }\end{array}$ & $u_{T\left(\mathrm{NO}_{3}\right)}$ & l & I & I & $\begin{array}{l}532 / 607 \mathrm{~nm}: \\
0.05 \mathrm{~K}\end{array}$ & $\begin{array}{l}532 / 607 \mathrm{~nm}: \\
0.1 \mathrm{~K}\end{array}$ \\
\hline $\begin{array}{l}\mathrm{NO}_{2} \\
\text { absorption } \\
\text { cross sections }\end{array}$ & $u_{T\left(\sigma \mathrm{NO}_{2}\right)}$ & I & I & I & $\begin{array}{l}355 / 387 \mathrm{~nm}: \\
0.01 \mathrm{~K}\end{array}$ & $\begin{array}{l}355 / 387 \mathrm{~nm}: \\
0.01 \mathrm{~K}\end{array}$ \\
\hline $\begin{array}{l}\text { Ancillary } \\
\mathrm{NO}_{2} \text { profile }\end{array}$ & $u_{T\left(N \mathrm{NO}_{2}\right)}$ & l & l & I & $\begin{array}{l}355 / 387 \mathrm{~nm}: \\
0.02 \mathrm{~K}\end{array}$ & $\begin{array}{l}355 / 387 \mathrm{~nm}: \\
0.02 \mathrm{~K}\end{array}$ \\
\hline $\begin{array}{l}\text { Ancillary } \\
\text { temperature } \\
\text { tie-on }\end{array}$ & $u_{T}(T \mathrm{TOP})$ & $\begin{array}{l}7 \mathrm{~km} \text { below } \\
\text { tie-on: } 7 \mathrm{~K}\end{array}$ & $\begin{array}{l}20 \mathrm{~km} \text { below } \\
\text { tie-on: } 0.8 \mathrm{~K}\end{array}$ & $\begin{array}{l}40 \mathrm{~km} \text { below } \\
\text { tie-on: } 0.04 \mathrm{~K}\end{array}$ & I & I \\
\hline $\begin{array}{l}\text { Acceleration } \\
\text { of gravity }\end{array}$ & $u_{T(g)}$ & $0-0.1 \mathrm{~K}$ & $0-0.1 \mathrm{~K}$ & $0-0.1 \mathrm{~K}$ & $0-0.1 \mathrm{~K}$ & $0-0.1 \mathrm{~K}$ \\
\hline $\begin{array}{l}\text { Molecular } \\
\text { mass of air }\end{array}$ & $u_{T\left(M_{\mathrm{a}}\right)}$ & $0-1 \mathrm{~K}$ & $0-0.05 \mathrm{~K}$ & $0-0.05 \mathrm{~K}$ & $0-0.05 \mathrm{~K}$ & $0-0.05 \mathrm{~K}$ \\
\hline $\begin{array}{l}\text { Total } \\
\text { (this work) }\end{array}$ & $u_{T}$ & $\begin{array}{l}\text { High-intensity: } \\
9 \mathrm{~K}\end{array}$ & $\begin{array}{l}\text { High-intensity: } \\
3 \mathrm{~K} \\
\text { Low-intensity: } \\
11 \mathrm{~K}\end{array}$ & $\begin{array}{l}\text { High-intensity: } \\
0.3 \mathrm{~K} \\
\text { Low-intensity: } \\
1.3 \mathrm{~K}\end{array}$ & $\begin{array}{l}\text { High-intensity: } \\
0.1-0.3 \mathrm{~K} \\
\text { Low-intensity: } \\
0.2-0.4 \mathrm{~K}\end{array}$ & $\begin{array}{l}\text { Low- } \\
\text { intensity: } \\
0.3-0.5 \mathrm{~K}\end{array}$ \\
\hline $\begin{array}{l}\text { Not included } \\
\text { (see Sect. 3.3) }\end{array}$ & I & I & I & I & $\begin{array}{l}0-5 \mathrm{~K} \\
\text { highly variable }\end{array}$ & $\begin{array}{l}0-5 \mathrm{~K} \\
\text { highly variable }\end{array}$ \\
\hline
\end{tabular}

is the Rayleigh cross section $(0.6 \mathrm{~K}$ at $10 \mathrm{~km}$, dark blue curve), then it becomes the detection noise of the Raman channel (up to $1 \mathrm{~K}$ at $30 \mathrm{~km}$ ), and the low-intensity Rayleigh channel $(0.9 \mathrm{~K}$ at $31-33 \mathrm{~km})$. After transitioning to the Rayleigh high-intensity channel, uncertainty is equally shared $(0.7 \mathrm{~K}$ at $33 \mathrm{~km})$ by saturation correction (green) and detection noise (red). Detection noise is then the dominant source of uncertainty all the way up to $75 \mathrm{~km}(\sim 1.5 \mathrm{~K})$, where it slowly gives way to the tie-on temperature uncer- tainty (grey curve), which increases to $20 \mathrm{~K}$ at the tie-on altitude.

When using the long-term database accumulated at MLO over the course of 20 years (for example to compute a climatology or to infer interannual variability or trends), uncertainty should be propagated to the climatology by first propagating each individual uncertainty component (the colored curves in the bottom-right plot) and then combining them. The detection noise (red curve) will be added in quadrature, while all other components are expected to be propagated 
linearly. As a consequence of this separate treatment, the climatological average will yield a reduced uncertainty owing to detection noise (random component), but not of the uncertainty owing to the systematic effects.

\section{Conclusion}

As part of three companion papers that reviewed the recommendations made to the NDACC lidar community for the standardization of vertical resolution and uncertainty, the present article covered the temperature uncertainty budget. The parameters impacting the lidar temperature retrieval include a number of atmospheric species, their scattering or absorption properties, as well as instrumental specifications. There is therefore no unique expression of uncertainty in the temperature lidar data processing algorithms that can be recommended. However, efforts were made here to produce generic recommendations that can be followed within the entire network.

The recommended definition of uncertainty is combined standard uncertainty as defined by the BIPM (JCGM 200, 2012; JCGM 100, 2008). One important aspect of our proposed approach is the ability to propagate all independent uncertainty components in parallel through the data processing chain. The individual uncertainty components are then combined together to form the combined standard temperature uncertainty, a mandatory variable of the proposed standardized NDACC lidar temperature uncertainty budget.

The individual uncertainty components identified herein comprise signal detection uncertainty, uncertainty due to saturation correction, background noise extraction, the merging of multiple channels, the absorption cross sections of ozone and $\mathrm{NO}_{2}$, the molecular extinction cross sections, the a priori use of ancillary air, ozone, and $\mathrm{NO}_{2}$ number density, the a priori use of ancillary temperature to tie-on the top of the profile, the acceleration of gravity, and the molecular mass of air. All these sources of uncertainty except detection noise imply correlated terms in the vertical dimension, which means that covariance terms must be taken into account when vertical filtering is applied.

The expression of the individual uncertainty components and their step-by-step propagation through the temperature data processing chain were thoroughly estimated by the ISSI team and reviewed here. The proposed formulations were quantitatively verified using simulated lidar signals and Monte Carlo experiments. This validation exercise, of which details are provided in the ISSI team report (Leblanc et al., 2016a), allowing the quantification of each uncertainty component, was propagated to the retrieved temperature profile in the presence of correlated variables.

In general, the largest uncertainty components include detection noise and temperature tie-on at the top of the profile, and saturation correction and molecular extinction at the bottom of the profile (see example in Table 3 and in Fig. 10).
Uncertainty contributions from absorption by $\mathrm{NO}_{2}$ and $\mathrm{O}_{3}$ are less significant, and the contributions from the acceleration of gravity and the molecular mass of air are negligible if those quantities are chosen accurately when introduced into the temperature retrieval.

It is strongly recommended that every source of uncertainty be reported in the NDACC-archived metadata files. In addition, individual standard uncertainty components contributing to the temperature combined uncertainty should be reported in the NDACC-archived data files if at all possible. For each reported uncertainty source, the systematic or random components should be reported in both the altitude and time dimensions. If using multiple profiles originating from the same instrument (for example to compute a climatology), the temperature uncertainty should be propagated to the end product by first propagating each individual uncertainty component, and then by combining them. In this process, the temperature uncertainty owing to detection noise will be added in quadrature, while all other uncertainty components are expected to be propagated linearly.

Due to the large variety of instrumentation, some uncertainty components may not have been treated in the present article. For those sources not treated here, the same generic approach as that proposed here should be used, and the individual components should be included in the uncertainty budget presented here following the same propagation principles.

As mentioned in our Part 1 companion paper (Leblanc et al., 2016b), many concepts described for ozone and temperature in our three companion papers can be applied to the retrieval of other NDACC lidar species such as water vapor (Raman and differential absorption techniques), temperature (rotational Raman technique, (Arshinov et al., 1983)), and aerosol backscatter ratio. We therefore recommend the formation of new working groups, possibly in the form of ISSI teams, whose tasks would be not only to extend the present work to the retrieval of other species, but also to propose a similar standardized treatment of uncertainty, accounting for the interference by particulate backscatter and extinction and by multiple scattering.

\section{Data availability}

The data used to produce the figures shown here are not publicly available. However, they can be obtained by contacting the first author at thierry.leblanc@jpl.nasa.gov.

Acknowledgements. This work was initiated in response to the 2010 call for international teams of experts in Earth and Space Science by the International Space Science Institute (ISSI) in Bern, Switzerland. It could not have been performed without the travel and logistical support of ISSI. Part of the work described in this paper was carried out at the Jet Propulsion Laboratory, California Institute of Technology, under agreements with the 
National Aeronautics and Space Administration. Part of this work was carried out in support of the VALID project. Robert J. Sica would like to acknowledge the support of the Canadian National Sciences and Engineering Research Council for support of the University of Western Ontario lidar work.

Edited by: H. Maring

Reviewed by: two anonymous referees

\section{References}

Ahmad, Z., McClain, C. R., Herman, J. R., Franz, B. A., Kwiatkowska, E. J., Robinson, W. D., Bucsela, E. J., and Tzortziou, M.: Atmospheric correction for $\mathrm{NO}_{2}$ absorption in retrieving water-leaving reflectances from the SeaWiFS and MODIS measurements, Appl. Opt., 46, 6504-6512, 2007.

Argall, P. S.: Upper altitude limit for Rayleigh lidar, Ann. Geophys., 25, 19-25, doi:10.5194/angeo-25-19-2007, 2007.

Arshinov, Y. F., Bobrovnikov, S. M., Zuev, V. E., and Mitev, V. M.: Atmospheric-temperature measurements using a pure rotational Raman lidar, Appl. Opt., 22, 2984-2990, 1983.

Bates, D. R.: Rayleigh-scattering by air, Planet Space Sci., 32, 785790, doi:10.1016/0032-0633(84)90102-8, 1984.

Bauer, R., Rozanov, A., McLinden, C. A., Gordley, L. L., Lotz, W., Russell III, J. M., Walker, K. A., Zawodny, J. M., LadstätterWeißenmayer, A., Bovensmann, H., and Burrows, J. P.: Validation of SCIAMACHY limb $\mathrm{NO}_{2}$ profiles using solar occultation measurements, Atmos. Meas. Tech., 5, 1059-1084, doi:10.5194/amt-5-1059-2012, 2012.

Bogumil, K., Orphal, J., Homann, T., Voigt, S., Spietz, P., Fleischmann, O. C., Vogel, A., Hartmann, M., Kromminga, H., Bovensmann, H., Frerick, J., and Burrows, J. P.: Measurements of molecular absorption spectra with the SCIAMACHY preflight model: instrument characterization and reference data for atmospheric remote-sensing in the $230-2380 \mathrm{~nm}$ region, J. Photochem. Photobiol. A, 157, 167-184, doi:10.1016/s10106030(03)00062-5, 2003.

Bracher, A., Sinnhuber, M., Rozanov, A., and Burrows, J. P.: Using a photochemical model for the validation of $\mathrm{NO}_{2}$ satellite measurements at different solar zenith angles, Atmos. Chem. Phys., 5, 393-408, doi:10.5194/acp-5-393-2005, 2005.

Brion, J., Chakir, A., Charbonnier, J., Daumont, D., Parisse, C., and Malicet, J.: Absorption Spectra Measurements for the Ozone Molecule in the 350-830 nm Region, J. Atmos. Chem., 30, 291299, doi:10.1023/a:1006036924364, 1998.

Brohede, S., McLinden, C. A., Berthet, G., Haley, C. S., Murtagh, D., and Sioris, C. E.: A stratospheric $\mathrm{NO}_{2}$ climatology from Odin/OSIRIS limb-scatter measurements, Can. J. Phys., 85, 1253-1274, doi:10.1139/p07-141, 2007.

Burkholder, J. B. and Talukdar, R. K.: Temperature dependence of the ozone absorption spectrum over the wavelength range 410 to $760 \mathrm{~nm}$, Geophys. Res. Lett., 21, 581-584, doi:10.1029/93g102311, 1994.

Burrows, J. P., Richter, A., Dehn, A., Deters, B., Himmelmann, S., and Orphal, J.: Atmospheric remote-sensing reference data from GOME - 2. Temperature-dependent absorption cross-sections of O-3 in the 231-794 nm range, J. Quant. Spectrosc. Ra., 61, 509517, doi:10.1016/s0022-4073(98)00037-5, 1999.
Chehade, W., Gorshelev, V., Serdyuchenko, A., Burrows, J. P., and Weber, M.: Revised temperature-dependent ozone absorption cross-section spectra (Bogumil et al.) measured with the SCIAMACHY satellite spectrometer, Atmos. Meas. Tech., 6, 30553065, doi:10.5194/amt-6-3055-2013, 2013.

D’Amico, G., Amodeo, A., Baars, H., Binietoglou, I., Freudenthaler, V., Mattis, I., Wandinger, U., and Pappalardo, G.: EARLINET Single Calculus Chain - overview on methodology and strategy, Atmos. Meas. Tech., 8, 4891-4916, doi:10.5194/amt-84891-2015, 2015.

Daumont, D., Brion, J., Charbonnier, J., and Malicet, J.: Ozone UV Spectroscopy I: Absorption Cross-Sections at Room Temperature, J. Atmos Chem., 15, 145-155, doi:10.1007/bf00053756, 1992.

Donovan, D. P., Whiteway, J. A., and Carswell, A. I.: Correction for nonlinear photon-counting effects in lidar systems, Appl. Opt., 32, 6742-6753, 1993.

Eberhard, W. L.: Correct equations and common approximations for calculating Rayleigh scatter in pure gases and mixtures and evaluation of differences, Appl. Opt., 49, 1116-1130, 2010.

Finger, F. G., Gelman, M. E., Wild, J. D., Chanin, M. L., Hauchecorne, A., and Miller, A. J.: Evaluation of NMC upperstratospheric temperature analyses using rocketsonde and lidar data, B. Am. Meteorol. Soc., 74, 789-799, 1993

Garcia, R. R., Marsh, D. R., Kinnison, D. E., Boville, B. A., and Sassi, F.: Simulation of secular trends in the middle atmosphere, 1950-2003, J. Geophys. Res.-Atmos., 112, D09301, doi:10.1029/2006jd007485, 2007.

Gorshelev, V., Serdyuchenko, A., Weber, M., Chehade, W., and Burrows, J. P.: High spectral resolution ozone absorption crosssections - Part 1: Measurements, data analysis and comparison with previous measurements around $293 \mathrm{~K}$, Atmos. Meas. Tech., 7, 609-624, doi:10.5194/amt-7-609-2014, 2014.

Gross, M. R., McGee, T. J., Ferrare, R. A., Singh, U. N., and Kimvilakani, P.: Temperature measurements made with a combined Rayleigh-Mie and Raman lidar, Appl. Opt., 36, 59875995, 1997.

Hauchecorne, A. and Chanin, M. L.: Density and temperature profiles obtained by lidar between $35-\mathrm{km}$ and $70-\mathrm{km}$, Geophys. Res. Lett., 7, 565-568, 1980.

Hedin, A. E.: Extension of the MSIS thermosphere model into the middle and lower atmosphere, J. Geophys. Res., 96, 1159-1172, doi:10.1029/90ja02125, 1991.

Hinkley, E. D.: Laser monitoring of the atmosphere, Topics in applied physics, 14, Springer-Verlag, 380 pp., 1976.

Hurst, D. F., Hall, E. G., Jordan, A. F., Miloshevich, L. M., Whiteman, D. N., Leblanc, T., Walsh, D., Vömel, H., and Oltmans, S. J.: Comparisons of temperature, pressure and humidity measurements by balloon-borne radiosondes and frost point hygrometers during MOHAVE-2009, Atmos. Meas. Tech., 4, 2777-2793, doi:10.5194/amt-4-2777-2011, 2011.

JCGM: International vocabulary of basic and general terms in metrology (VIM), Tech. Rep. JCGM 200:2008, International Bureau of Weights and Measures (BIPM), 2008.

JCGM: Evaluation of measurement data - Guide to the expression of uncertainty in measurement (GUM), Tech. Rep. JCGM 100: 2008, International Bureau of Weights and Measures (BIPM), 2008 . 
JCGM: International Vocabulary of Metrology - Basic and General Concepts and Associated Terms (VIM3), Tech. Rep. JCGM 200: 2012, International Bureau of Weights and Measures (BIPM), 2012.

Keckhut, P., Hauchecorne, A., and Chanin, M. L.: A criticalreview of the database acquired for the long-term surveillance of the middle atmosphere by the French Rayleigh lidars, J. Atmos. Ocean. Tech., 10, 850-867, doi:10.1175/15200426(1993)010<0850: acrotd>2.0.co;2, 1993.

Keckhut, P., McDermid, S., Swart, D., McGee, T., GodinBeekmann, S., Adriani, A., Barnes, J., Baray, J. L., Bencherif, H., Claude, H., di Sarra, A. G., Fiocco, G., Hansen, G., Hauchecorne, A., Leblanc, T., Lee, C. H., Pal, S., Megie, G., Nakane, H., Neuber, R., Steinbrecht, W., and Thayer, J.: Review of ozone and temperature lidar validations performed within the framework of the Network for the Detection of Stratospheric Change, J. Environ. Monit., 6, 721-733, doi:10.1039/b404256e, 2004.

Keckhut, P., Randel, W. J., Claud, C., Leblanc, T., Steinbrecht, W., Funatsu, B. M., Bencherif, H., McDermid, I. S., Hauchecorne, A., Long, C., Lin, R., and Baumgarten, G.: An evaluation of uncertainties in monitoring middle atmosphere temperatures with the ground-based lidar network in support of space observations, J. Atmos. Sol.-Terr. Phy., 73, 627-642, doi:10.1016/j.jastp.2011.01.003, 2011.

Leblanc, T., McDermid, I. S., Hauchecorne, A., and Keckhut, P.: Evaluation of optimization of lidar temperature analysis algorithms using simulated data, J. Geophys. Res., 103, 6177-6187, 1998.

Leblanc, T., Sica R., van Gijsel, A., Godin-Beekmann, S., Haefele, A., Trickl, T., Payen, G., and Liberti, G.: Standardized definition and reporting of vertical resolution and uncertainty in the NDACC lidar ozone and temperature algorithms, ISSI Team on NDACC Lidar Algorithms Report, available for download at: http://www.issibern.ch/teams/ndacc/ISSI_Team_Report. htm (last access: 22 August 2016), 2016a.

Leblanc, T., Sica, R. J., van Gijsel, J. A. E., Godin-Beekman, S., Haefele, A., Trickl, T., Payen, G., and Gabarrot, F.: Proposed standardized definitions for vertical resolution and uncertainty in the NDACC lidar ozone and temperature algorithms Part 1: Vertical resolution, Atmos. Meas. Tech., 9, 4029-4049, doi:10.5194/amt-9-4049-2016, 2016b.

Leblanc, T., Sica, R. J., van Gijsel, J. A. E., Godin-Beekmann, S., Haefele, A., Trickl, T., Payen, G., and Liberti, G.:Proposed standardized definitions for vertical resolution and uncertainty in the NDACC lidar ozone and temperature algorithms - Part 2: Ozone DIAL uncertainty budget, Atmos. Meas. Tech., 9, 4051-4078, doi:10.5194/amt-9-4051-2016, 2016c.

Lemoine, F. C., Kenyon, S. C., Factor, J. K., Trimmer, R. G., Pavlis, N. K., Chinn, D. S., Cox, C. M., Klosko, S. M., Luthcke, S. B., Torrence, M. H., Wang, Y. M., Williamson, R. G., Pavlis, E. C., Rapp, R. H., and Olson, T. R.: The Development of the Joint NASA GSFC and the National Imagery and Mapping Agency (NIMA) Geopotential Model EGM96, Tech. Rep., 1998.
Mattis, I., D’Amico, G., Baars, H., Amodeo, A., Madonna, F., and Iarlori, M.: EARLINET Single Calculus Chain - technical - Part 2: Calculation of optical products, Atmos. Meas. Tech., 9, 30093029, doi:10.5194/amt-9-3009-2016, 2016.

Mohr, P. J., Taylor, B. N., and Newell, D. B.: CODATA recommended values of the fundamental physical constants: 2006, Rev. Mod. Phys., 80, 633-730, doi:10.1103/RevModPhys.80.633, 2008.

Müller, J. W.: Dead-time problems, Nucl. Instr. and Meth., 112, 4757, doi:10.1016/0029-554x(73)90773-8, 1973.

NIMA: Department of Defense World Geodetic System 1984, Tech. Rep., 3rd Edition, 2000, 175 pp., available at: http://earth-info. nga.mil/GandG/publications/tr8350.2/wgs84fin.pdf (last access: 22 August 2016), 2000.

Press, W. H., Flannery, B. P., Teukolsky, S. A., and Vetterling W. T.: Numerical Recipes: The Art of Scientific Computing (1st ed.), New York, Cambridge University Press, ISBN-13: 978-0-52188068-8, 1986.

Reichardt, J. and Reichardt, S.: Determination of cloud effective particle size from the multiple-scattering effect on lidar integration-method temperature measurements, Appl. Opt., 45, 2796-2804, doi:10.1364/ao.45.002796, 2006.

Sica, R. J. and Haefele, A.: Retrieval of temperature from a multiple-channel Rayleigh-scatter lidar using an optimal estimation method, Appl. Opt., 54, 1872-1889, doi:10.1364/ao.54.001872, 2015.

Sica, R. J., Zylawy, Z. A., and Argall, P. S.: Ozone Corrections for Rayleigh-Scatter Temperature Determinations in the Middle Atmosphere, J. Atmos. Ocean. Tech., 18, 1223-1228, doi:10.1175/1520-0426(2001)018<1223:OCFRST>2.0.CO;2, 2001.

Strauch, R. G., Derr, V. E., and Cupp, R. E.: Atmospheric temperature measurement using raman backscatter, Appl. Opt., 10, 2665-2669, doi:10.1364/ao.10.002665, 1971.

Strutt, J. W. (Lord Rayleigh): XXXIV. On the transmission of light through an atmosphere containing small particles in suspension, and on the origin of the blue of the sky, Philos. Mag., 47, 375384, doi:10.1080/14786449908621276, 1899.

Vandaele, A. C., Hermans, C., Simon, P. C., Carleer, M., Colin, R., Fally, S., Merienne, M. F., Jenouvrier, A., and Coquart, B.: Measurements of the $\mathrm{NO}_{2}$ absorption cross-section from $42000 \mathrm{~cm}(-$ 1) to $10000 \mathrm{~cm}(-1)(238-1000 \mathrm{~nm})$ at $220 \mathrm{~K}$ and $294 \mathrm{~K}$, J. Quant. Spectrosc. Ra., 59, 171-184, doi:10.1016/s00224073(97)00168-4, 1998.

Whiteman, D. N., Demoz, B., Schwemmer, G., Gentry, B., Di Girolamo, P., Sabatino, D., Comer, J., Veselovskii, I., Evans, K., Lin, R. F., Wang, Z., Behrendt, A., Wulfmeyer, V., Browell, E., Ferrare, R., Ismail, S., and Wang, J.: Raman Lidar Measurements during the International H2O Project. Part II: Case Studies, J. Atmos. Ocean Tech., 23, 170-183, doi:10.1175/jtech1839.1, 2006. 